\title{
Predicting Levels of Crude Protein, Digestibility, Lignin and Cellulose in Temperate Pastures Using Hyperspectral Image Data
}

\author{
Susanne Thulin',2, Michael J. Hill ${ }^{3}$, Alex Held4, Simon Jones', Peter Woodgate ${ }^{5}$ \\ ${ }^{1}$ Department of Geospatial Sciences, RMIT University, Melbourne, Australia \\ ${ }^{2}$ Brockmann-Geomatics Sweden AB, Kista, Sweden \\ ${ }^{3}$ Department of Earth System Science and Policy, University of North Dakota, Grand Forks, USA \\ ${ }^{4}$ AusCover, CSIRO Marine and Atmospheric Research, Canberra, Australia \\ ${ }^{5}$ Cooperative Research Centre for Spatial Information, Carlton, Australia \\ Email: susanne.thulin@brockmann-geomatics.se
}

Received 23 January 2014; revised 24 February 2014; accepted 11 March 2014

Copyright (C) 2014 by authors and Scientific Research Publishing Inc.

This work is licensed under the Creative Commons Attribution International License (CC BY). http://creativecommons.org/licenses/by/4.0/

(c) (i) Open Access

\section{Abstract}

Hyperspectral sensors provide the potential for direct estimation of pasture feed quality attributes. However, remote sensing retrieval of digestibility and fibre (lignin and cellulose) content of vegetation has proven to be challenging since tissue optical properties may not be propagated to the canopy level in mixed cover types. In this study, partial least squares regression on spectra from HyMap and Hyperion imagery were used to construct predictive models for estimation of crude protein, digestibility, lignin and cellulose concentration in temperate pastures. HyMap and Hyperion imagery and field spectra were collected over four pasture sites in southern Victoria, Australia. Co-incident field samples were analyzed with wet chemistry methods for crude protein, lignin and cellulose concentration, and digestibility was calculated from fiber determinations. Spectral data were subset based on sites and time of year of collection. Reflectance spectra were extracted from the hyperspectral imagery and collated for analysis. Six different transformations including derivatives and continuum removal were applied to the spectra to enhance absorption features sensitive to the quality attributes. The transformed reflectance spectra were then subjected to partial least squares regression, with full cross-validation "leave-one-out" technique, against the quality attributes to assess effects of the spectral transformations and post-atmospheric smoothing techniques to construct predictive models. Model performance between spectrometers, subsets and attributes were assessed using a coefficient of variation (CV), - the interquantile (IQ) range of the attribute values divided by the root mean square error of prediction (RMSEP) from the models. The predictive models with the highest CVs were obtained for digesti- 
bility for all spectra types, with HyMap the highest. However, models with slightly lower CVs were obtained for crude protein, lignin and cellulose. The spectral regions for diagnostic wavelengths fell within the chlorophyll well, red edge, and $2000-2300 \mathrm{~nm}$ ligno-cellulose-protein regions, with some wavelengths selected between the 1600 and $1800 \mathrm{~nm}$ region sensitive to nitrogen, protein, lignin and cellulose. The digestibility models with the highest CV's had confidence intervals corresponding to $\pm 5 \%$ digestibility, which constitutes approximately $30 \%$ of the measured range. The cellulose and lignin models with the highest CV's also had similar confidence intervals but the slopes of the prediction lines were substantially less than 1:1 indicating reduced sensitivity. The predictive relationships established here could be applied to categorizing pasture quality into range classes and to determine whether pastures are above or below for example threshold values for livestock productivity benchmarks.

\section{Keywords}

Pasture Quality; Crude Protein; Digestibility; Lignin; Cellulose; Hyperspectral Remote Sensing; Partial-Least Squares Regression

\section{Introduction}

Using remote sensing to retrieve key components of the feed budget for livestock grazing enterprises is an important tool for efficient management of livestock, as well as in renewable resource application, e.g. [1] [2]. There is already a long history of research on estimation of grassland biomass from spectral information, e.g. [3]-[7] and methods have recently been derived for the description of key components of the feed budget, the growth rate of the pasture [8] and the quantity of available feed on offer [9]. However, the other important component required to complete the "total" feed budget is a measure of feed quality in pastures. For decades NIR methods have been used for in situ uses of spectroscopy in chemical analyses, e.g. [10]-[12]. In the era of multi-spectral sensors, feed quality could only be inferred indirectly from vegetation indices such as the NDVI as measures of the amount/cover of green photosynthetic vegetation, from ad hoc information on the seasonal changes in feed quality, and in situ chemistry from feed testing agencies.

The rising prospects in the next five years for routine availability of high quality satellite based hyperspectral sensors provide the potential for use of imaging spectroscopy techniques to provide more direct measurement of feed quality, and for linking in-situ data to remote-sensing derived information, to help characterize and even quantify the heterogeneity of pasture feed quality attributes across the landscape. Hyperspectral sensing provides a larger number of wavelengths that are physically linked to electron transitions or vibrations and overtones of absorptions of molecules of different biochemical constituents and therefore provide high levels of fidelity in chemical detection and quantification, e.g. [1] [13] and together with lidar data and emerging analysis techniques will become increasingly better at mapping the fingerprints of different types of vegetation species [14].

Pasture quality may be defined at many levels of detail, but fundamentally it is characterized by nutrient content, digestibility and fibre content [15]. While there are numerous important nutrients in pastures, nitrogen is one of the most important, and is often represented in feed quality assessments by the crude protein content, a measure that includes both true protein and non-protein nitrogen [16] [17]. Digestibility indicates how much of a forage will be digested, i.e. the extent to which it is absorbed in the animal's digestive tract, and is usually measured as dry matter digestibility [15]. The fibrous or cell wall fraction of plants consists of cellulose, hemicellulose, lignin and cutin and 98\% of this fraction is indigestible [18]. Cellulose and lignin are negatively correlated with digestibility and crude protein content. Lignin is a complex polymer of phenylpropanoid units and it has a key structural role in plants. Because lignin is indigestible and impermeable to water it also reduces overall digestibility of plants. Despite the negative correlation with digestibility, lignin, by itself, does not fully explain digestibility [18].

Vegetation has six major absorption features [19] at approximately 480, 670, 1200, 1730, 2100 and $2300 \mathrm{~nm}$. The first three of these are sensitive to chlorophyll a and b electron transitions, chlorophyll absorption and water. The remaining three spectral absorption features are generally sensitive to nitrogen, lignin and cellulose concen- 
trations. These absorption features can be enhanced by transformations such as continuum removal and normalization to the area and/or centre wavelength of the features [20].

Remote sensing of plant canopy nitrogen has progressed, largely due to the key association with chlorophyll and the increased sensitivity of spectrometers at these wavelengths, e.g. [21]-[26]. However, retrieval of digestibility and vegetation fibre (lignin and cellulose) content from spectral analysis has proven more difficult, e.g. [27]-[29], partially since tissue optical properties may not be propagated to the canopy level in mixed cover [30]. Features and/or spectral differences in the 2000 - $2400 \mathrm{~nm}$ wavelengths have been used to measure and differentiate senescent vegetation and soil. For example, wavelengths between 2239 - 2372 nm, related to oil/wax absorption, were shown to be essential for mapping of South Australian arid vegetation associations using HyMap data [31]. The $2100 \mathrm{~nm}$ cellulose feature and 2200 hydroxyl feature are important for distinguishing stubble and soil [32] and spectral signatures above $2000 \mathrm{~nm}$ are important in fractional cover unmixing [33]. However, the presence of water features, and the mix of closely packed wavelengths sensitive to chemical bonds, vibrations and small absorptions within a mixture of any complex compounds, along with the need for very high signal to noise ratio have limited successful quantitative retrievals to date.

In recent studies, [34] [35] obtained relative prediction errors in the 3\% - 5\% range for predictive models of fibre fractions and digestibility of ryegrass swards using sub-leaf level spectral analysis. Reference [1] recently obtained moderately good statistics for a predictive model for crude protein $\left(R^{2}=0.6\right)$ and ADF $\left(R^{2}=0.65\right)$ from field spectra in temperate pastures. In hyperspectral analysis of tropical pastures in the Brazilian Amazon, ligno-cellulose absorption features had the highest correlations with (high fibre) senesced biomass [2].

Analysis of field spectrometer data [36] for prediction of pasture quality attributes in temperate pastures of southern Australia led the authors to suggest that, in principle, prediction of digestibility, and lignin and cellulose content of pastures, should be based around two main spectral responses. These are in the chlorophyll absorption and red edge regions, that indirectly predict changes from photosynthetic to non-photosynthetic vegetation that are correlated with increasing fibre content, and in the SWIR wavelengths that directly predict the presence of lignin and cellulose from absorption features. Savanna studies, [37] [38] confirm the importance of this approach with SWIR, chlorophyll and red edge wavelengths effective for predicting N, P, K, CA and Mg nutrient contents in African grasses.

Since there are virtually no studies that attempt to retrieve lignin, cellulose and digestibility attributes of pastures from either field or image spectra, there is a need for research in order to fully characterize absorption responses and sensitivities. This study, conducted 2002-2006, attempts to predict wavelengths for pasture quality attributes of temperate pastures using partial least squares regression (PLSR) on different types of spectra; ASD field spectra (ASD field spectra convolved to image bands, and on spectra collected from HyMap and Hyperion imagery). The selected wavelengths derived from the predictive models are compared and their relationship to established absorption features is evaluated. The effectiveness of the predictive PLSR models for estimation of crude protein, digestibility, lignin and cellulose concentrations is presented with emphasis on the differences between spectra types but also in relation to different transformation models employed.

\section{Material and Methods}

\subsection{Study Sites}

The study sites were located in Western Victoria (Australia) close to the town of Hamilton and in eastern Victoria at Ellinbank (Figure 1(c), green and red stars respectively). The main study site was located at the Pastoral and Veterinary Institute (PVI) farm paddocks including their Long-Term Phosphate Experiment (LTPE) paddocks and some privately owned paddocks adjacent to the PVI Figures 1(a) and (b). An additional site in Western Victoria was located at Vasey, $35 \mathrm{~km}$ north of Hamilton, on a privately owned sheep farm involved in a collaborative pasture research project with the Department of Primary Industries Victoria from 1996-2002 as part of a national research project on sustainable grazing systems Figure 1(d). The single site in Eastern Victoria was located at Ellinbank, a dairy research facility Figure 1(e). At the time of imaging, the property was completing a complex rotational grazing study which afforded many paddocks and different pasture states for sampling.

The pastures of the Hamilton area are made up of mixtures of introduced cool season grasses (perennial ryegrass-Loliumperenne, phalaris-Phalarisaquatica, orchard grass-Dactylisglomerata) and legumes (subterranean clover-Trifoliumsubterraneum, and white clover-Trifoliumrepens), along with numerous weedy annuals 


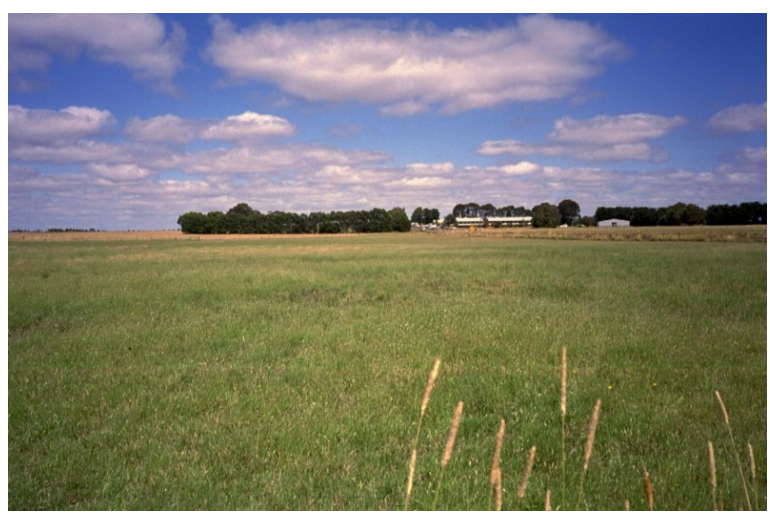

(a)

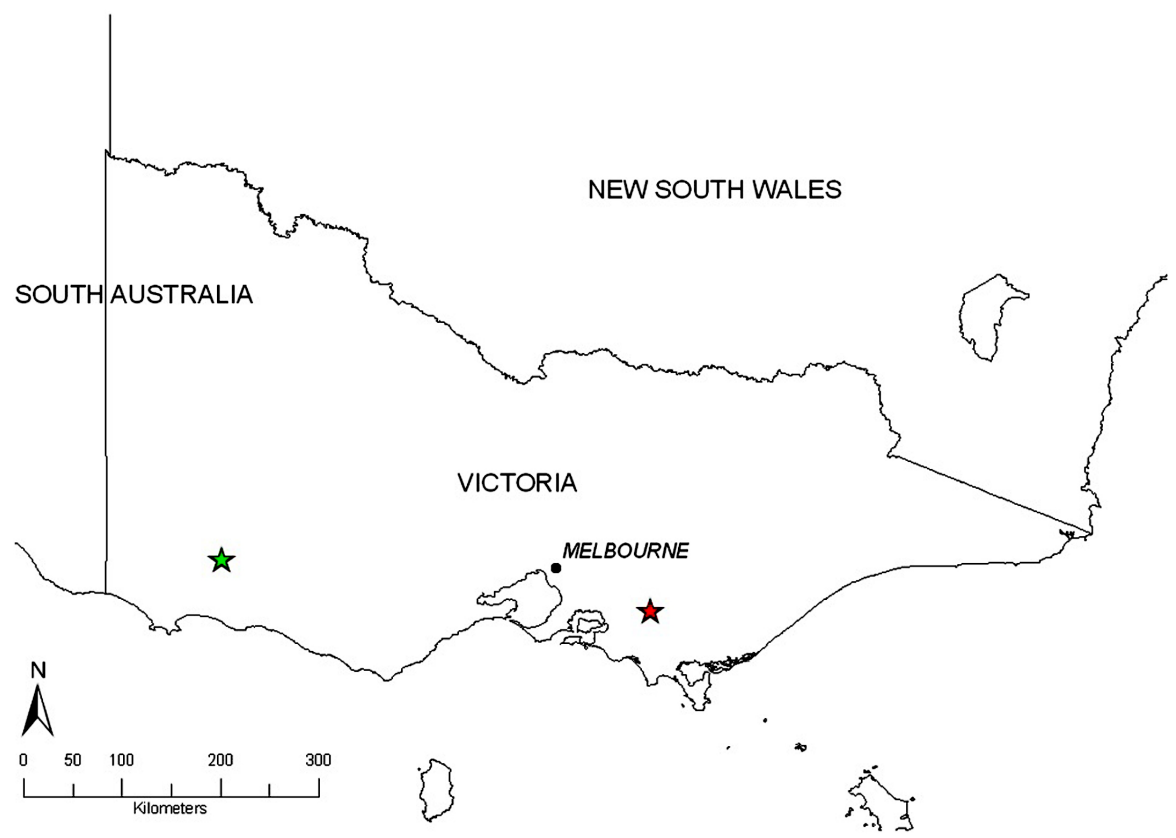

(c)

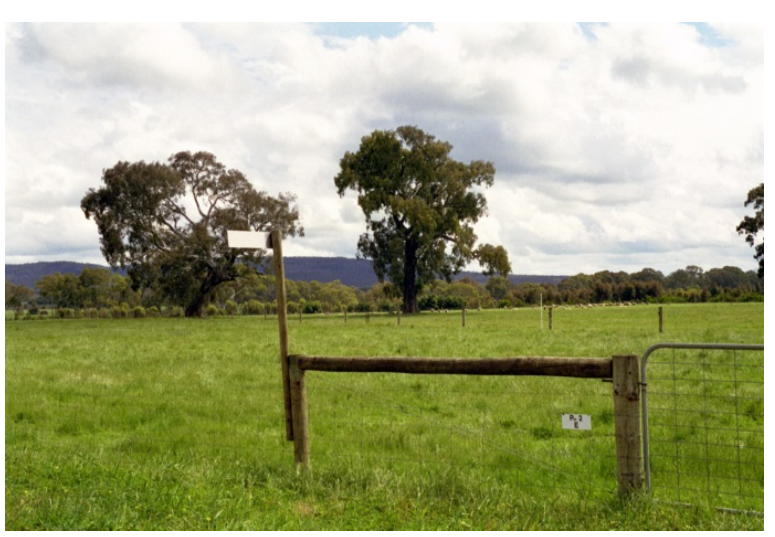

(d)

(e)

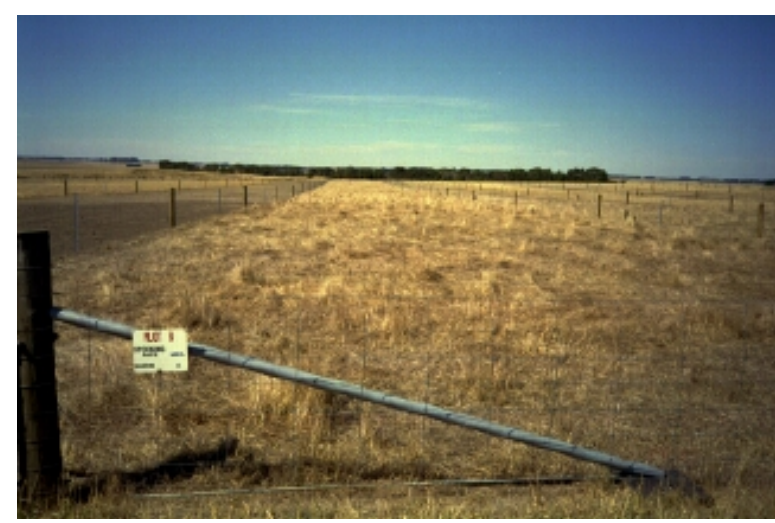

(b)

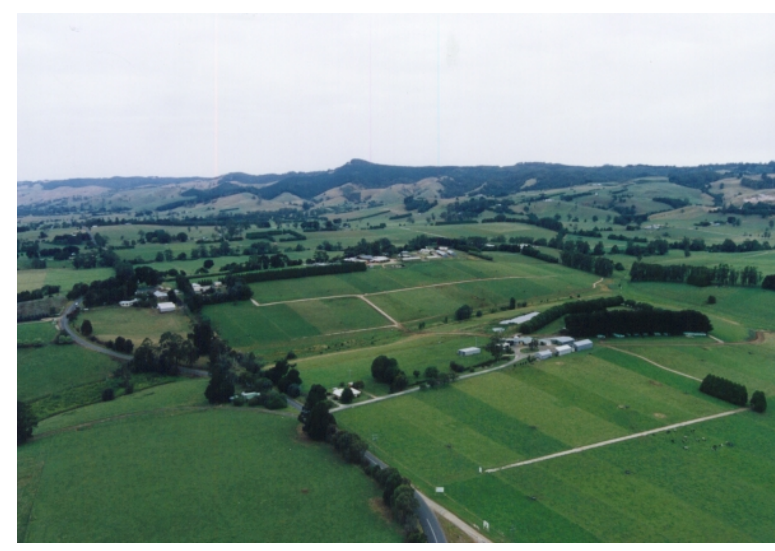

Figure 1. Photos of sites and location map. (a) Pastoral and Veterinary Research Institute December 2000; (b) Hamilton, LTPE, March 2001; (c) Map of Victoria showing general location of western sites (PVI, LTPE, Vasey) with green star and eastern site (Ellinbank) with red star; (d) Vasey, December 2000; and (e) Ellinbank, December 2000 (copyright Skyworks Aerial Photography Pty Ltd). 
(e.g. barley grass-Hordeumleporinum), and are used for grazing of sheep, beef cattle and dairy cows. The pastures at Ellinbank are predominantly made up of perennial ryegrass and white clover and are used for dairying.

\subsection{Image Data}

The hyperspectral image data used in this study were captured by two different sensors, the HyMap airborne system and the Hyperion spectrometer on the EO-1 satellite. The details of image capture are shown in Table 1. The HyMap sensor data consists of 126 spectral bands over the 440 - $2500 \mathrm{~nm}$ electromagnetic range, with approximately $15 \mathrm{~nm}$ spectral resolution, and a maximum signal to noise ratio (SNR) of $>1000: 1$ over a 512 pixel swath in the atmospheric windows at 50\% reflectance [39]. On December 5, 2000, the HyMap sensor recorded images of the PVI farm area, over the Vasey farm in Western Victoria and of Ellinbank in Eastern Victoria. On March 15, 2001, the LTPE study site was imaged. The spatial resolutions of the HyMap images were 2.8 or 2.9 meters.

The Hyperion hyperspectral sensor [40] is carried on board NASA's Earth Observing One (EO-1). It is a "push broom" type scanner and consists of a single telescope and two grating spectrometers, one visible/nearinfrared (VNIR) and one short-wave infrared (SWIR) spectrometer providing 242 raw spectral bands. The instantaneous field of view (IFOV) of the Hyperion sensor is $0.642^{\circ}$ wide by $42.55 \mu$ radians in the satellite forward direction. This creates a nominal frame or pixel size of 30 meters; where each column of data is created by a single detector. Hyperion data are processed to a number of product levels [41], in this study the Level 1_B product was used. The Hyperion image was captured over the PVI January 19, 2002.

\subsection{Image Pre-Processing}

Hyperspectral image processing steps/tasks were executed using the methods of [42]-[46]. Image pre-processing included removal of bad bands, removal or fixing of bad pixels, and de-smiling and de-striping in the SWIR above $2000 \mathrm{~nm}$ (Hyperion only). Atmospheric correction and conversion to apparent reflectance was performed followed by enhancement by noise removal/smoothing. Geo-rectification was performed prior to extraction of image spectra for analysis. ENVI/IDL ${ }^{\circledR} 3.5$ - 4.1 image analysis software [47] was used for image analysis and image pre- and post-atmospheric processing. Apparent reflectance for the HyMap images was calculated using HYCORR2 ${ }^{\circledR}$ software. It is based on the Atmosphere REMoval program (ATREM) and Empirical Flat Field Optimal Reflectance Transformation [48] [49]. ACORN4.1® software, based on MODTRAN 4 was used for atmospheric correction of the Hyperion image.

Two main noise removal/smoothing transformations were applied after atmospheric correction to the HyMap and Hyperion data, MNF (Maximum Noise Fraction transformation and EFFORT (Empirical Flat Field Optimal Reflectance Transformation) polishing. Both techniques have been reported to produce good results. MNF has been used to effectively remove noise [45] and EFFORT polishing applies a mild linear correction to each band, boot-strapped from the data, which attempts to improve the accuracy of the apparent reflectance data and the visual appearance [50].

For the HyMap images, EFFORT polishing was applied in two ways; firstly, to atmospherically correct images as part of HYCORR2 and, secondly applied to the MNF transformed images using EFFORT polishing in ENVI. Field spectra captured with a field spectrometer (ASD Fieldspec ${ }^{\circledR}$ PRO FR) at the time of the imaging missions were used as reality boost spectra for EFFORT polishing within ENVI-field spectra can assist in creating a better fit for the spectral smoothing to remove unwanted noise. Different spectra were selected for the four HyMap images depending on the nature of vegetation present in the study areas.

Table 1. HyMap and Hyperion flight mission details.

\begin{tabular}{|c|c|c|c|c|c|}
\hline Study site/Image & Flight Date & Spatial resolution(meters) & Flight EST/(GMT + 10) & Heading degree & Latitude/Longitude \\
\hline \multicolumn{6}{|l|}{ НyМар } \\
\hline PVI & 2000-12-05 & 2.9 & $11.20 \mathrm{am}$ & $-117-118$ & $-37.82 / 142.07$ \\
\hline Vasey & 2000-12-05 & 2.9 & $10.47 \mathrm{am}$ & -117 & $-37.40 / 141.92$ \\
\hline LTPE & 2001-03-16 & 2.8 & $2.34 \mathrm{pm}$ & $118-120$ & $-37.84 / 142.09$ \\
\hline Ellinbank & 2000-12-05 & 2.8 & $3.42-3.57 \mathrm{pm}$ & $290-293$ & $-38.25 / 145.93$ \\
\hline \multicolumn{6}{|l|}{ Hyperion } \\
\hline PVI & 2002-01-19 & 30 & $10.42 \mathrm{am}$ & & $-37.82 / 142.07$ \\
\hline
\end{tabular}


Five spectra were used in the processing of the Vasey and PVI HyMap images, whereas only 3 were used for the LTPE HyMap image processing due to the dryness of the vegetation in this image.

For Hyperion, EFFORT with reality boost as implemented in ENVI was run with a single spectra, i.e. the average of all the field spectra $(n=46)$ captured during the Hyperion overpass. Five spectra were used in the processing of the Vasey and PVI HyMap images, whereas only 3 were used for the LTPE HyMap image processing due to the dryness of the vegetation in this image. For Hyperion, EFFORT with reality boost as implemented in ENVI was run with a single spectra, i.e. the average of all the field spectra $(n=46)$ captured during the Hyperion overpass.

The HyMap data was georeferenced using the flight ephemeris data and a built-in routine in ENVI/Geo- reference for input geometry [47]. A geometry lookup table (GLT) created from an input geometry file (IGM) that is supplied with the imagery was used and a nearest neighbor resampling rectification performed. The images were all rectified to a common projection and coordinate system (UTM, WGS84 datum) using the built in functions mentioned above. Since the geometry of Hyperion data is quite simple, georeferencing of the Hyperion images was carried out by affine or bi-linear transformations using a map base, which gave approximately 0.5 pixel registration accuracy [43]. In addition the HyMap and Hyperion images were registered further to GIS layers of paddock boundaries.

Pre-processed HyMap and Hyperion reflectance images were either used directly for extraction of spectra (NONE), or subjected to two different smoothing procedures: MNF smoothing (MNF) and combined MNF and EFFORT smoothing using field spectra to boost (MNF-EFF). The choice of smoothing approach is a trade-off between removing noise and removing valid details, depending on the application. In order to not risk losing detail less smoothing is recommended but this means leaving more noise which can override the signal. Therefore several methods were tested.

Based on analysis of ASD field spectra [36], six transforms were applied to spectra creating 7 versions of spectra (including reflectance R): derivative of reflectance (R-D), derivative of the logarithm of the reciprocal of reflectance (LOG1R-D), for the entire spectrum the derivative of continuum removal (CR-D) and derivative of the depth of the continuum-removed absorption feature (DEP-D), and for six major vegetation absorption features [19] [20] continuum removed absorption normalized to area (BNA) and its derivative (BNA-D). For all continuum removed spectra standard start and end points were used to facilitate comparison. A subset of spectra called HyMap-2000 was created by excluding the image spectra derived from the HyMap image acquired in March 2001 because of very different (high) albedo and limited pasture quality attribute ranges in the senesced pastures.

\subsection{Field Sampling}

Pasture canopy spectra were captured with a full range $(400$ - $2500 \mathrm{~nm})$ ASD $^{\mathrm{TM}}$ field spectrometer within two days of the HyMap imaging times for each site and on the day of the Hyperion overpass. The PVI research farm was also visited in a separate field campaign in October 2002 [36]. Ground spectra were captured both as point based spectra using a tripod set up and as average spectra recorded while slowly walking with the spectrometer forward and backward over paddock areas (30 meter diameter at 50 meter spacing) to provide reference data for Hyperion image spectra. The fraction of ground showing was between 0 and approximately $20 \%$. Corresponding pasture samples (so called toe cuts) were collected at intervals of a couple meters for all ASD ${ }^{\mathrm{TM}}$ canopy spectra, trying to ensure sampling of dominant species while still being representative of the imaged areas. To facilitate analysis with spectra extracted from the hyperspectral imagery, additional samples were collected along paddock transects established for other pasture research (Vasey and Ellinbank 2000, LTPE 2001) and around point locations (PVI 2000). The locations of these points and of the transect start- and end-points in the imagery were established with GPS and digital GIS layers created (Figure 2).

The pasture samples were analyzed for a wide range of feed quality and biochemical constituents including digestibility, crude protein and fibre measures with the latter ones used to calculate cellulose and lignin concentrations. The assay results, expressed in \% dry matter (DM) for the data subsets used in the study show large variations both in ranges and distribution types (Table 2 and Figure 3).

The samples are dominated by observations made at mature stages of pasture development and the ranges and descriptive statistics, where high values are lacking for digestibility and crude protein in the assays corresponding to image spectra. Consequently ranges of the image spectra samples are in general narrower. 


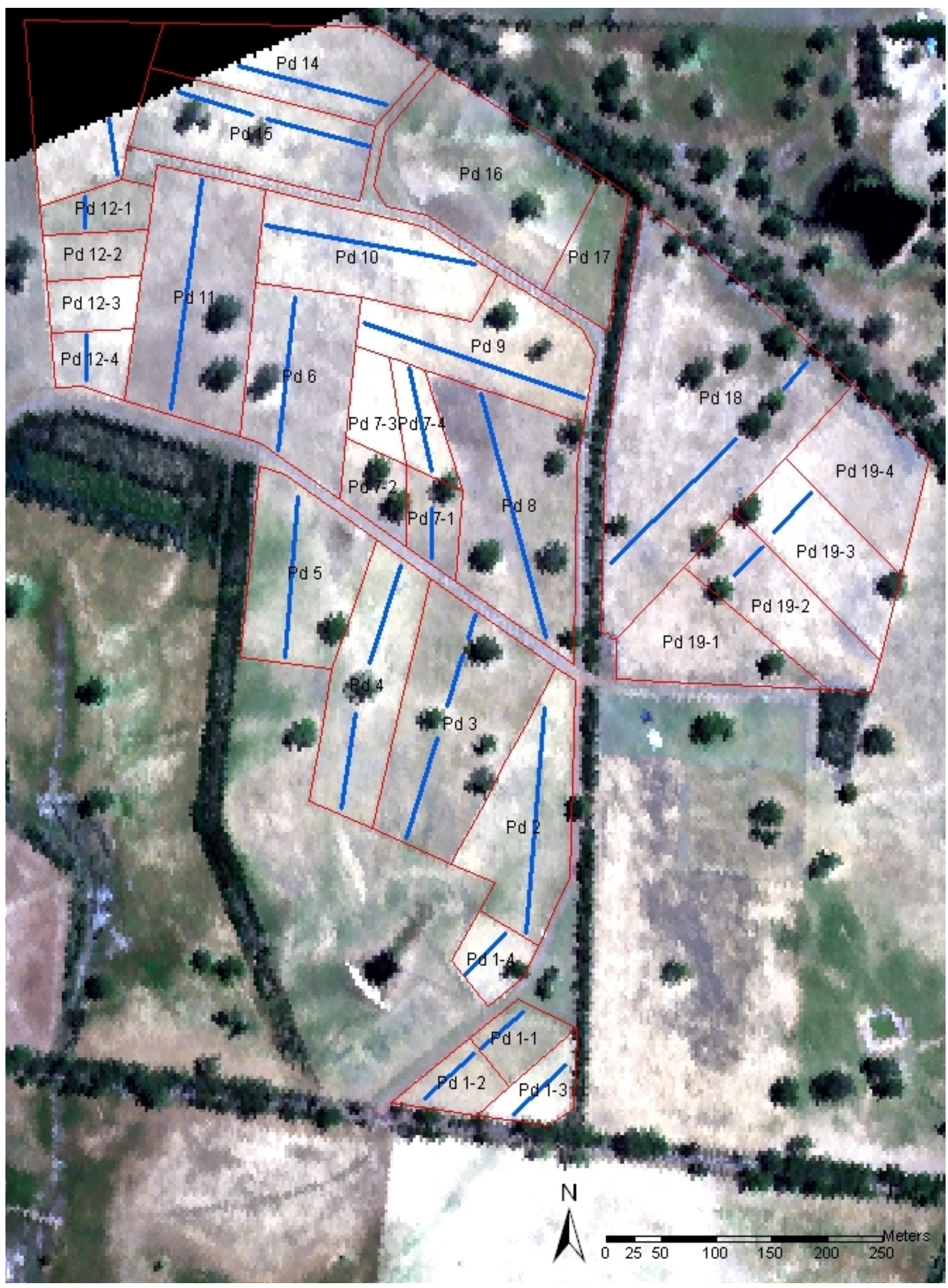

Figure 2. True colour Vasey HyMap image (December 2000) showing vector overlay of paddock boundaries (red) and pasture sampling transect lines (blue) as ROIs. 
Table 2. Table of assay distribution statistics for the data sets included in the study.nis the number of samples and IQ range $(20,80)$ is the interquantile range between 20 th and 80th percentiles.

\begin{tabular}{|c|c|c|c|c|c|c|c|}
\hline Pasture quality attribute (\% DM) & Spectra data set & $n$ & mean & median & $\min$ & $\max$ & IQ range $(20,80)$ \\
\hline \multirow[t]{4}{*}{ crude protein } & ASD-2002 & 45 & 12.17 & 11.14 & 5.76 & 30.45 & 7.79 \\
\hline & HyMap-all & 72 & 9.38 & 10.03 & 3.35 & 16.66 & 7.10 \\
\hline & НyМар-2000 & 56 & 10.72 & 11.09 & 4.20 & 16.66 & 4.54 \\
\hline & Hyperion-2002 & 46 & 8.81 & 8.73 & 4.20 & 12.67 & 4.46 \\
\hline \multirow[t]{4}{*}{ digestibility } & ASD-2002 & 45 & 64.42 & 63.73 & 44.99 & 85.56 & 18.39 \\
\hline & HyMap-all & 72 & 55.85 & 57.17 & 35.88 & 71.35 & 20.03 \\
\hline & НyМар-2000 & 56 & 59.86 & 59.64 & 45.23 & 71.35 & 10.16 \\
\hline & Hyperion-2002 & 46 & 59.53 & 59.92 & 47.75 & 66.60 & 7.51 \\
\hline \multirow[t]{4}{*}{ lignin } & ASD-2002 & 45 & 5.30 & 4.75 & 2.15 & 15.96 & 3.06 \\
\hline & HyMap-all & 72 & 5.87 & 5.50 & 2.40 & 10.50 & 4.73 \\
\hline & НyМар-2000 & 56 & 5.04 & 4.12 & 2.40 & 9.46 & 3.15 \\
\hline & Hyperion-2002 & 46 & 7.30 & 6.74 & 3.19 & 19.26 & 3.91 \\
\hline \multirow[t]{4}{*}{ cellulose } & ASD-2002 & 45 & 26.04 & 25.99 & 17.71 & 36.68 & 8.61 \\
\hline & HyMap-all & 72 & 31.22 & 29.09 & 24.63 & 44.25 & 7.47 \\
\hline & НyМар-2000 & 56 & 28.82 & 28.62 & 24.63 & 33.25 & 2.93 \\
\hline & Hyperion-2002 & 46 & 25.81 & 26.43 & 13.52 & 35.78 & 5.58 \\
\hline
\end{tabular}

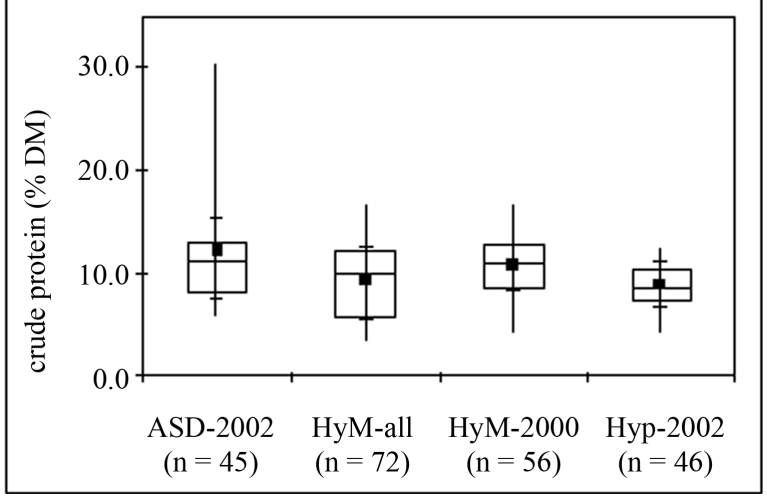

(a)

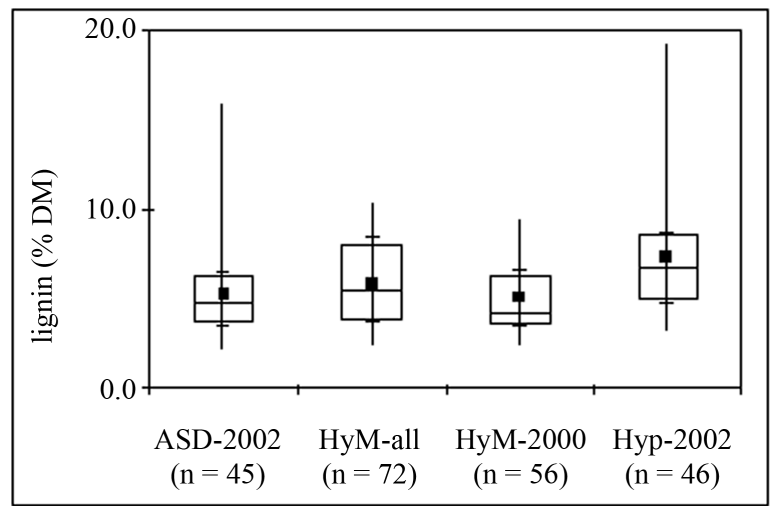

(c)

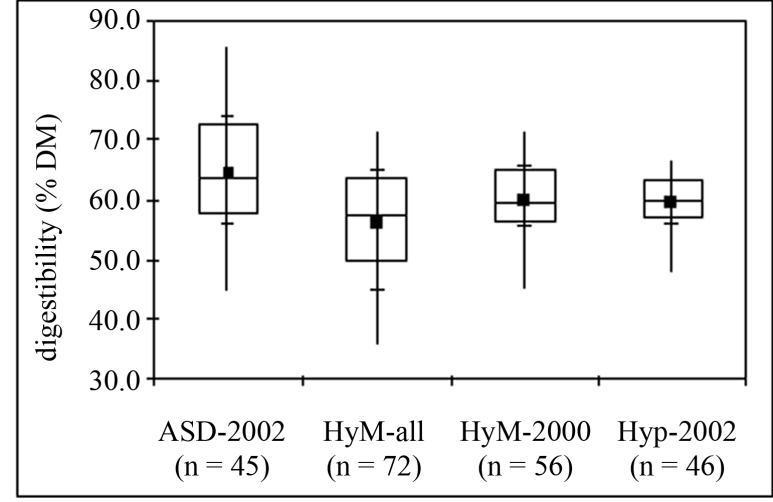

(b)

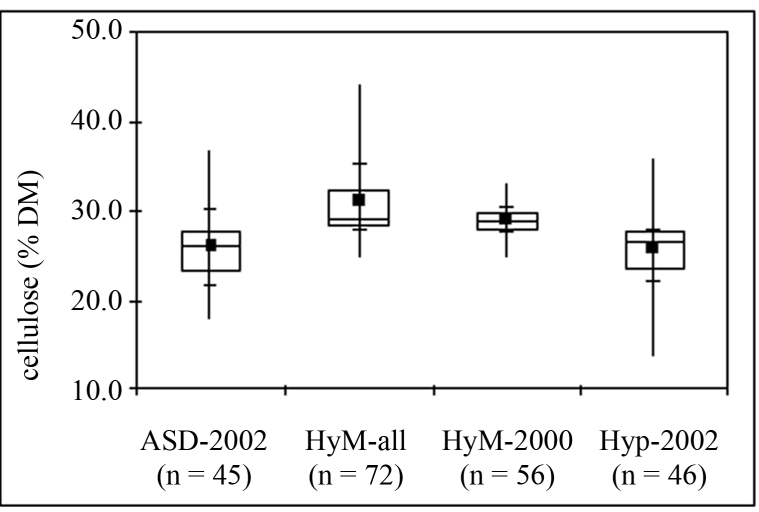

(d)

Figure 3. Box and whisker plots showing descriptive statistics corresponding to the four sample subsets (a) crude protein; (b) digestibility; () lignin; (d) cellulose. Min and Max (bar ends), Mean (square dot), Median (box cross bar), 25th and 75th percentiles (box), 20th and 80th percentiles (cross bars). 
These are generally more representative of the status of the paddocks than the in situ spectra that can have higher values for specific smaller plant canopies. Consequently ranges of the image spectra samples are in general narrower.

The ranges for digestibility and cellulose are comparable to ranges for pasture species as reported by other researchers [19] [20] [51]. The typical leaf nitrogen concentrations of the ryegrass component of dairy pasture in New Zealand have been observed to range from $2 \%-5 \%$ by [24], which corresponds roughly to a crude protein content of $12.5 \%$ - 30\%. The research data contain several lower values. The difference in range between in situ spectra samples and image spectra samples are notable for crude protein and lignin.

\subsection{Transformation of Collections of Spectra}

The collection of reflectance spectra and a number of transformations of reflectance had been created from the ASD data. Analyses of the relationship between spectral data and pasture assays included stepwise multiple linear regression (SMLR) and partial least squares regression (PLSR). Spectral transformation such as continuum removal and derivatives enhanced the results [36].

Spectra corresponding to field sampling locations were extracted from each of the smoothed and transformed HyMap and Hyperion images using digital transect lines and sample locations transformed to pixel-based regions of interest (ROIs in ENVI). A total of 72 ROIs were defined for the HyMap acquisitions: the total was made up of 23 at Ellinbank, 20 at Vasey, 13 at PVI and 16 at LTPE. From the Hyperion imagery, 56 ROIs were created and image spectra statistics extracted.

For further processing and derivation of transformations a collection of spectra of mean reflectance (R) was created from the ROIs. From R pseudo absorbance (LOG 1-R) and continuum removed reflectance (CR) was calculated. From continuum removal of the spectral regions corresponding to the six vegetation specific absorption features spectral collections were created of continuum removed reflectance normalized to the area of the absorption feature (BNA) and to the wavelength with the largest depth value (DEP) to further test the usefulness of this method [20] [52]. The collection of spectra used for further analysis was complemented with respective derivatives, i.e. R-D, LOG 1-R-D, CR-D, BNA-D and DEP-D.

\subsection{Convolution of Field Spectra to HyMap and Hyperion Bands}

ASD field spectra were convolved to HyMap and Hyperion spectrometer band passes to determine if prediction models developed from the ASD spectra could be portable to the image scales, and to compare these with the performance of models developed directly from image spectra. Based on prior analysis [36], the subsets of ASD canopy spectra acquired in 2002 were used for the band pass convolution analysis. Resampling and convolving many narrow bands to fewer wider bands causes an increase in the SNR and can have a smoothing effect on high resolution spectral data [53]. This process is sometimes described as "degrading” since a reduction in spectral resolution is the result [54]. In preparation, instead of removing the "bad" band regions corresponding to atmospheric water absorption (1340 nm - $1430 \mathrm{~nm}$ and $1790 \mathrm{~nm}$ - $1965 \mathrm{~nm}$ ), the reflectance values were linearly interpolated between the start and end of these noisy regions. This avoided unwanted effects resulting from resampling to HyMap and Hyperion band passes in the regions where field spectrometer data were noisy.

The sensor band pass functions describe the way in which radiance is recorded and divided between the sensor bands. The details of the principal process for calculation of the band pass functions are provided in [46]. Field spectra were resampled to HyMap and Hyperion band passes using ENVI and a spectral library of binning weights over the same number of bands and sampling distance $(1 \mathrm{~nm})$ between 350 to $2500 \mathrm{~nm}$ as the ASD data. The spectral libraries were derived from ancillary data supplied with the imagery from the sensor manufacturers. The convolved ASD field spectra were subjected to the same transformations as were applied to ASD field and HyMap and Hyperion image spectra.

\subsection{Partial Least Squares Regression}

PLSR is a spectral decomposition/data compression technique related to principal component analysis (PCA) and principal component regression (PCR) and falls under the heading of bilinear ("soft”) modelling [55]. It is a type of factor analysis where a large set of data variables is reduced to a smaller set of principal components (PCs), also called latent variables or factors. Each PC is obtained by maximising the covariance between Y and 
all possible linear functions of $\mathrm{X}$.

The main advantages of PLSR compared to multiple linear regression are:

- PLSR is insensitive to collinearity between spectral variables;

- the number of spectral variables can far exceed the number of samples; and

- PLSR can be used on small samples sets with non-parametric properties.

PLSR was carried out using the Unscrambler ${ }^{\circledR}$ software Version 9.1.0.3. After some initial testing of different models the number of allowed PCs/factors was set to 10 to limit processing time. The PLS regression was run with full "leave-one-out" cross validation, where each sample is excluded once and used for prediction and the PLS calibration and prediction statistics are calculated on the average of all runs. The cross-validation provides the number of optimum PCs for a model as suggested by the software and is based on the minimum prediction error for the Y-variable (here pasture quality attribute), a function of the estimation error and the model error [56] in Unscrambler denoted root mean square error of prediction, RMSEP.

PLSR statistics such as RMSEP, the correlation coefficient R, regression coefficients and factor- or X-loadings were derived for the PLSR prediction models for each subset of spectra and pasture quality attribute. When models from different spectral transformations had similar evaluation statistics, models with higher explained variance and/or fewer PLS factors were preferred over models with slightly lower RMSEPs. Less complicated models relative to predictive power, i.e. higher model efficiency, are preferred in practical settings to achieve good model utility for prediction of other samples [55].

As applied in The Unscrambler ${ }^{\circledR}$ PLSR analysis provides a choice when using full cross-validation to assess and save significant X-variables (spectral bands) derived from Marten's Uncertainty test based on a jack-knifing principal [56]. The test provides a method for reducing the number of X-variables with little influence in the model. The PLSR process was subsequently re-run for each transform using only the identified significant $\mathrm{X}$-variables.

In PLSR loading weights are calculated for the X-variables as part of the calculation of the model regression coefficients. The loading weights define the impact each X-variable/band has on each model PC [55]. As a large loading weight means a high contribution of the $\mathrm{X}$-variable to the equation it may thus describe spectral variation relevant to the Y-variable containing the attribute concentrations [57].

The PLSR model X-loading weights for each of the main PCs were used to identify regions of sensitivity and compare with established wavelengths of elemental absorption. By sorting the wavelengths by X-loading value, wavelengths with relatively stronger influence could be identified. Scatterplots were constructed for the X-loading weights for each PC and displayed in different colours with arrows highlighting wavelengths with a possible physical relationship to the attribute.

\subsection{Comparison of Results}

As a measure of relative error and predictive capacity a coefficient of variation (CV) based on the ratio between the interquantile (IQ) attribute range (20th and 80th percentiles) and RMSEP was used when comparing results between data subsets and between pasture quality attributes. This CV was used instead of the more commonly derived CV based on the ratio of the standard deviation (SD) and RMSEP, for example in [58] Park et al., (1998), to avoid violating parametric assumptions, for example normal distribution. The IQ range was determined appropriate as it retains approximately $60 \%$ of the distribution, which is roughly the same as \pm 1 standard deviation (66.3\%) and it avoided long tails in non-normal pasture quality attribute distributions of some of the subsets. A CV based on SD/RMSEP greater than 2.5 has been reported as indicating models with good qualitative predictive capacity and above 3.0 providing potential for quantitative estimates ([58] Park et al., 1998). These values correspond approximately to a CV (IQ range/RMSEP) of 4.1 and 4.9 respectively (calculated from relationship to SD/RMSEP ratios of sample subsets with normal distribution).

\section{Results}

\subsection{Field Spectra Convolved to HyMap and Hyperion Band Passes}

The PLSR predictive models for pasture quality attributes derived from field spectra convolved to HyMap and Hyperion band pass functions were similar in terms of R, RMSEP and CV to the models from the original ASD spectra, except for lignin where the results for the band pass models produced lower CVs (Table 3). This is 
Table 3. Comparison of prediction models derived from in situ spectra (ASD), resampled in situ spectra (ASD-x-bin), HyMap image spectra (HyM) and Hyperion image spectra (Hyp), using the models with the highest coefficient of variation (CV) for each spectra type pasture quality attribute. The post-atmospheric treatment versions are given in brackets with the spectra type and the transform model is listed in the third column. The best model is highlighted in bold. PLSR statistics are provided by $\mathrm{R}$ and RMSEP. IQ range is the interquantile range $(20,80)$ of the pasture attribute values. CV is IQ range/RMSEP and is used for assessment of model performance. -sig denotes transform model derived from significant X-variables (bands) only. Models with the highest CV are marked in bold for each attribute. CV's > 4.1 are generally regarded as indicating an effective model and are highlighted in grey.

\begin{tabular}{|c|c|c|c|c|c|c|}
\hline \multirow[t]{2}{*}{$\begin{array}{l}\text { Pasture quality } \\
\text { attribute }\end{array}$} & \multirow[t]{2}{*}{$\begin{array}{c}\text { Spectra type } \\
\text { (post-atmospheric treatment version) }\end{array}$} & \multirow[t]{2}{*}{$\begin{array}{l}\text { Transform }^{\mathrm{a}} \\
\text { (model) }\end{array}$} & \multicolumn{2}{|c|}{$\begin{array}{c}\text { PLSR } \\
\text { statistics }\end{array}$} & \multirow{2}{*}{$\begin{array}{c}\begin{array}{c}\text { Attribute distribution } \\
\text { statistic }\end{array} \\
\text { IQ-range } \\
\end{array}$} & \multirow[b]{2}{*}{ CV } \\
\hline & & & $\mathbf{R}$ & RMSEP & & \\
\hline \multirow{6}{*}{$\begin{array}{l}\text { Crude Protein } \\
\text { (\% of DM) }\end{array}$} & ASD-2002 & BNA-sig & 0.80 & 3.18 & 7.79 & 2.45 \\
\hline & ASD-2002-HyM-bin & DEP-D & 0.88 & 2.58 & 7.79 & 3.02 \\
\hline & ASD-2002-Hyp-bin & DEP-D-sig & 0.85 & 2.83 & 7.79 & 2.76 \\
\hline & HyM-all (MNF-EFF) & CR-D-sig & 0.92 & 1.41 & 7.10 & 5.03 \\
\hline & HyM-2000 (NONE) & R-D-sig & 0.87 & 1.44 & 4.54 & 3.15 \\
\hline & Hyp-2002 (MNF-EFF) & CR-D-sig & 0.80 & 1.31 & 4.46 & 3.40 \\
\hline \multirow{6}{*}{$\begin{array}{l}\text { Digestibility } \\
\text { (\% of DM) }\end{array}$} & ASD-2002 & DEP-D-sig & 0.91 & 3.94 & 18.39 & 4.67 \\
\hline & ASD-2002-HyM-bin & R-sig & 0.88 & 4.55 & 18.39 & 4.04 \\
\hline & ASD-2002-Hyp-bin & R-D & 0.89 & 4.45 & 18.39 & 4.13 \\
\hline & HyM-all (MNF-EFF) & $\mathbf{R}$ & 0.96 & 2.71 & 20.03 & 7.38 \\
\hline & HyM-2000 (MNF) & $\mathrm{R}$ & 0.91 & 2.42 & 10.16 & 4.20 \\
\hline & Hyp-2002 (MNF) & R-D-sig & 0.86 & 2.28 & 7.51 & 3.30 \\
\hline \multirow{3}{*}{$\begin{array}{l}\text { Lignin } \\
\text { (\% of DM) }\end{array}$} & ASD-2002 & LOG1R-D-sig & 0.68 & 1.87 & 3.06 & 1.63 \\
\hline & ASD-2002-HyM-bin & R-sig & 0.56 & 2.10 & 3.06 & 1.46 \\
\hline & ASD-2002-Hyp-bin & R-sig & 0.57 & 2.10 & 3.06 & 1.46 \\
\hline \multirow{9}{*}{$\begin{array}{l}\text { Cellulose } \\
\text { (\% of DM) }\end{array}$} & HyM-all (MNF-EFF) & LOG1R-D-sig & 0.90 & 1.01 & 4.73 & 4.70 \\
\hline & HyM-2000 (HYCORR-EFF) & BNA-D-sig & 0.86 & 0.95 & 3.15 & 3.31 \\
\hline & Hyp-2002 (NONE) & CR-D-sig & 0.46 & 2.97 & 3.91 & 1.32 \\
\hline & ASD-2002 & BNA-sig & 0.87 & 2.37 & 8.61 & 3.63 \\
\hline & ASD-2002-HyM-bin & LOG1R-D-sig & 0.91 & 2.36 & 8.61 & 3.65 \\
\hline & ASD-2002-Hyp-bin & CR-D-sig & 0.91 & 2.00 & 8.61 & 4.30 \\
\hline & HyM-all (NONE) & DEP-D-sig & 0.92 & 1.91 & 7.47 & 3.90 \\
\hline & HyM-2000 (NONE) & CR-D-sig & 0.76 & 1.17 & 2.93 & 2.50 \\
\hline & Hyp-2002 (NONE) & R-D-sig & 0.75 & 3.11 & 5.58 & 1.80 \\
\hline
\end{tabular}

${ }^{\mathrm{a}} \mathrm{R}$ Reflectance, R-D $1{ }^{\text {st }}$ derivative R, LOG1R-D 1st derivative Log(1/R),CR-D 1st derivative continuum-removed R, BNA (continuum removed absorption feature R (six major absorption features), bands normalised to feature area), BNA-D 1st derivative BNA, DEP-D 1st derivative of DEP (depth of continuum removed absorption feature, full spectrum).

explained perhaps as a result of the smoothing effect of the convolution, all of the HyMap and Hyperion model with the highest CVs were based on different transforms to the original field spectra models.

The PLSR model X-loading weights for each of the main PCs were used to identify regions of sensitivity and compared with established wavelengths of elemental absorption. Since most of the predictive models for lignin showed very low CV values (Table 3), only X-loading data for crude protein, digestibility and cellulose are shown (Figures 4-6). For crude protein (Figure 4) the $2060 \mathrm{~nm}$ protein absorption feature was identified as important by all band pass versions, $1730 \mathrm{~nm}$ was in common to the original and Hyperion band pass versions, and $2294 \mathrm{~nm}$ to the HyMap and Hyperion band pass versions.

For digestibility (Figure 5), wavelengths in the red edge and the 2260 - $2280 \mathrm{~nm}$ regions had high X-loadings and were common between the original and Hyperion band pass versions. The 1690 and 1694 nm protein absorption wavelengths had high X-loadings for HyMap and Hyperion band passes. Wavelengths marked by the PC X-loadings for the original band pass model (DEP-D-sig) and the HyMap band pass model were very different. Wavelengths marked by the Hyperion band pass model included most of the individual wavelengths with high X-loadings in the original and HyMapband pass models.

For cellulose (Figure 6), the main wavelengths with high X-loadings in common between the models for the three band pass versions were the 2270 and $2280 \mathrm{~nm}$ cellulose absorption wavelengths. Wavelengths with high $\mathrm{X}$-loadings in the red edge were common to HyMap and Hyperion band pass versions. However, the model from the original band pass had high X-loadings at $460 \mathrm{~nm}$. 


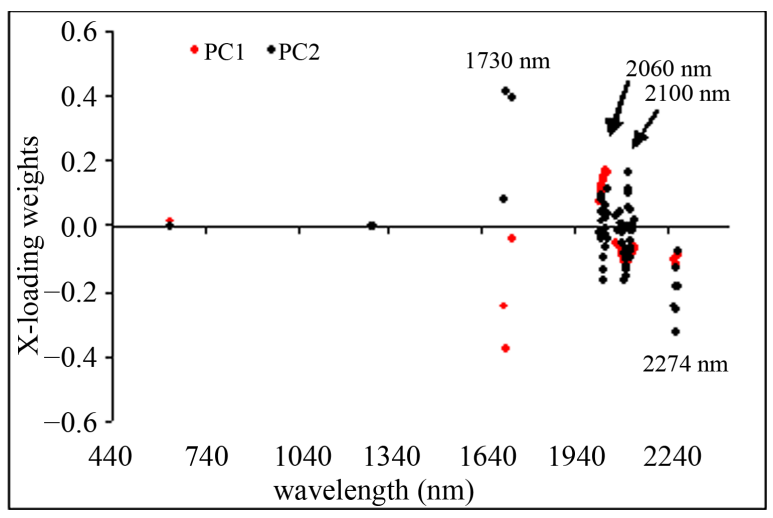

(a)

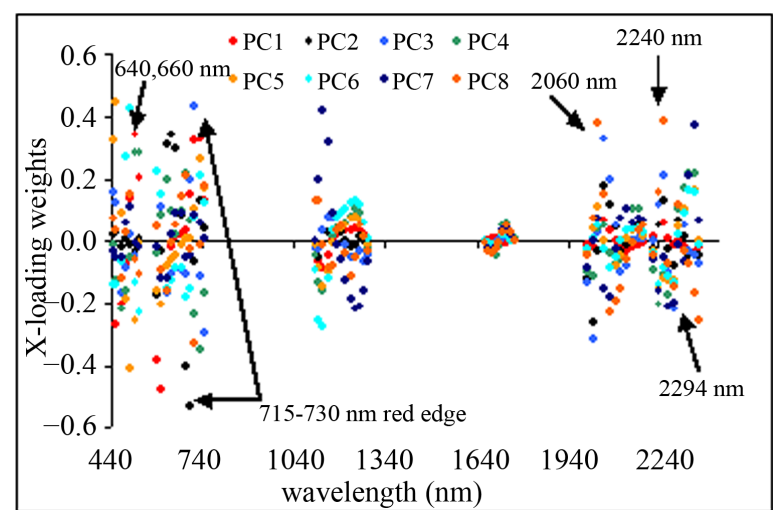

(b)

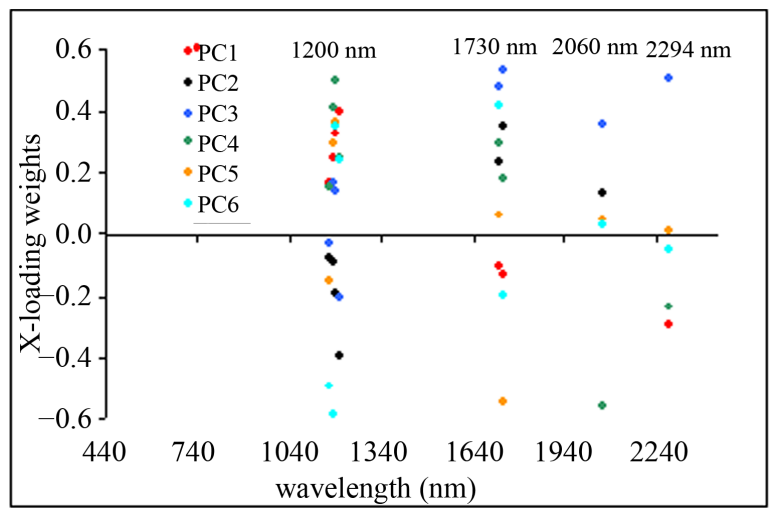

(c)

Figure 4. PLSR X-loading weights for important wavelengths associated with best models for crude protein for (a) original field spectra (ASD-2002-BNA-sig) and field spectra binned to (b) HyMap (DEP-D) and to (c) Hyperion (DEP-D-sig) band pass functions.

\subsection{HyMap Image Spectra Analysis}

The PLSR results showed that six of the eight HyMap models with the highest CVs for the four attributes were based on derivative transforms (Table 3). However, for digestibility, the models with the highest CVs (7.38, HyMap-all and 4.20, HyMap 2002) involved MNF or MNF in combination with EFFORT smoothing and reflectance. For cellulose the models without smoothing showed the highest CVs used an MNF smoothing, although the general performance was lower with CV's of 3.90 and 2.50. For lignin, the LOG1R-D and BNA-D transforms and MNF-EFF and HYCORR-EFF smoothing respectively produced the highest CVs for the HyMap subsets, 4.70 and 3.31 respectively. If a threshold for predictive capacity was set at CV > 4.1, then an effective model was obtained for the December 2000 spectra only for digestibility (Table 3), whilst if all spectra were included the models for crude protein and even lignin were acceptable.

Whilst, the correlation for the models with the highest CVs was very similar between crude protein, digestibility and lignin, there were significant differences in the RMSEP and CV values, providing for additional model discrimination (Table 4). Raw reflectance performed just as well as the mathematical transforms, especially for digestibility. The lower predictive capacity for cellulose may be related to the low interquantile range (2.93).

The range has a large effect on the CVs obtained; for example for digestibility it is nearly double 20.02 for the HyMap-all subset versus 10.16 for the HyMap-2000 resulting in CVs of 7.38 and 4.20 respectively. The March 2001 samples contribute substantially to these increased ranges in the HyMap-all data.

Plots of predicted versus actual values for the models based on HyMap spectra for 2000 for each pasture quality attribute showed that the combination of data from the different sites contribute to the overall dynamic range and therefore provide a better basis for the development of models effective for prediction of future unknown samples than would each separate site considered separately (Figure 7). For example, the data from the dairy site at Ellinbank (black dots) as part of the HyMap-2000 subset tend to be high in crude protein and digestibility, 


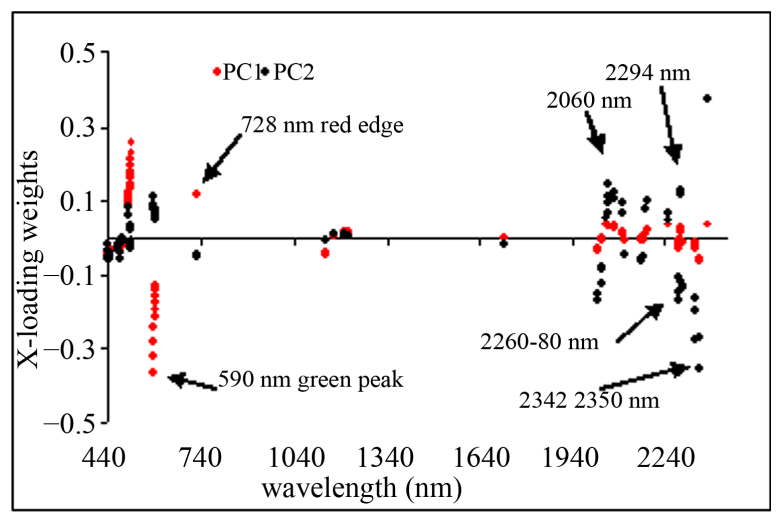

(a)

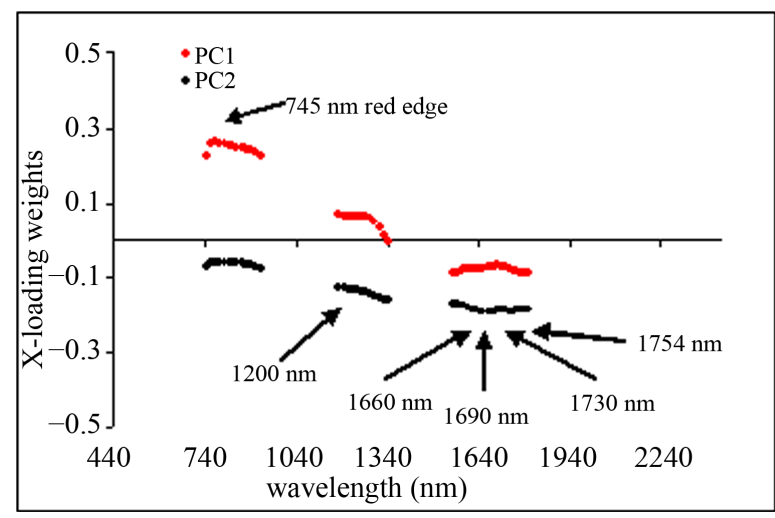

(b)

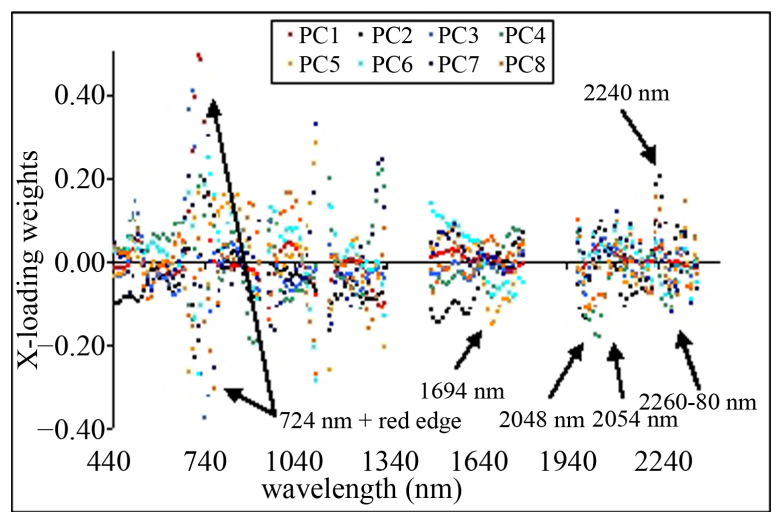

(c)

Figure 5. PLSR X-loading weights for important wavelengths associated with best models for digestibility for (a) original field spectra (ASD-2002-DEP-D-sig) and field spectra binned to (b) HyMap (R-sig) and to (c) Hyperion (R-D) band pass functions.

and low in fibre, whereas the Vasey data contribute to the correlation for lower levels. The data points are in general relatively tightly and evenly spaced around the regression lines for digestibility and crude protein, whereas for cellulose the dispersion is larger for values between 32\% - 33\% (of DM).For lignin, the point spread is larger and clustering of points prominent, indicating that phenology, as the major controlling factor, and consequently lignin concentration, is similar within sites. This indicates a less reliable model despite a comparable CV results (3.15) for crude protein and (3.31) for lignin for the Hymap-2000 subset.

\subsection{Hyperion Image Spectra Analysis}

There was substantial variation in RMSEP and R among the PLSR models from Hyperion image spectra with the highest CVs. However, only the model for cellulose met the criteria for a CV > 4.1 (Table 3). Only digestibility had a correlation between predicted and observed data that exceeded 0.80. Results from comparison of smoothing approaches on Hyperion spectra (data not given), showed that models with highest CVs were obtained for digestibility and lignin when MNF or MNF-EFF smoothing was applied, which is reflected in the results presented in Table 3, i.e. five out of six pasture attributes. All three of the cellulose models with the highest CV for the spectra derived from Hyperion and Hymap spectra (highest R, lowest RMSEP) did not have smoothing applied.

The plots of predicted versus observed pasture quality attributes illustrate the differences in model quality (Figure 8). The digestibility model exhibits the closest agreement between the modelled and observed data i.e. the smallest deviation from the 1:1 relationship line. The point spread was larger for crude protein, although a reasonable $\mathrm{R}$ value was obtained (Table 4). The slope of the relationship resulted in over prediction of low values and under prediction of cellulose values in the upper ranges, both indicating a lack of reliable prediction. The points were mostly arranged in a circular cluster suggesting the relationship between measured and 


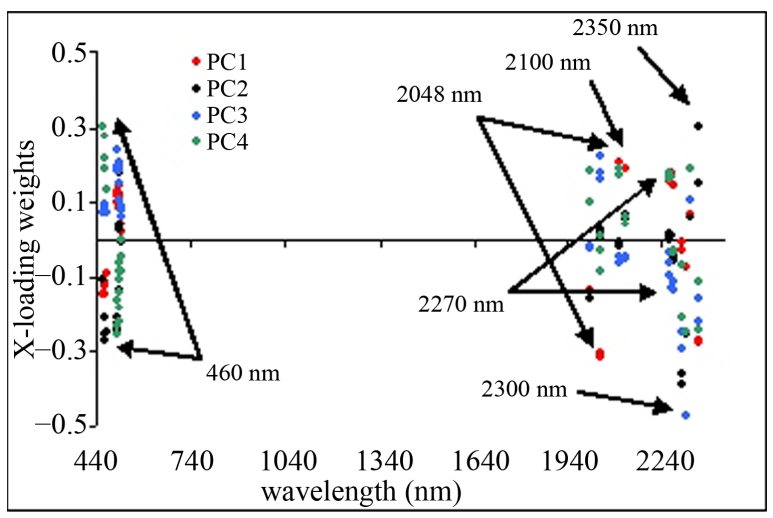

(a)

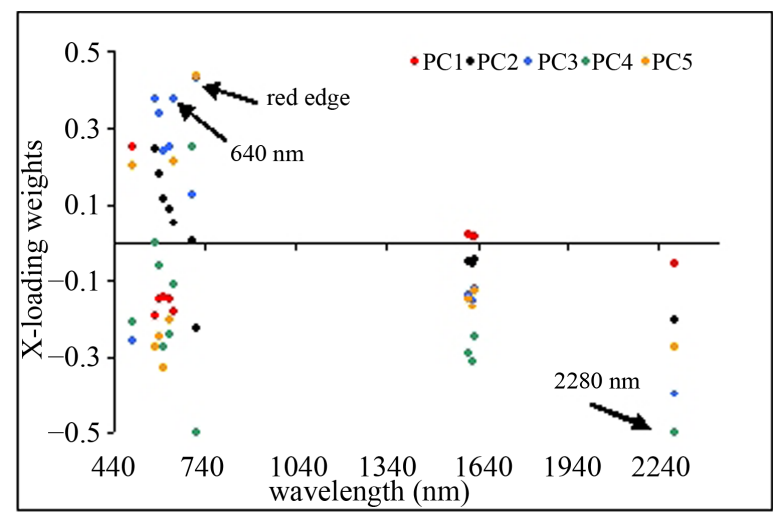

(b)

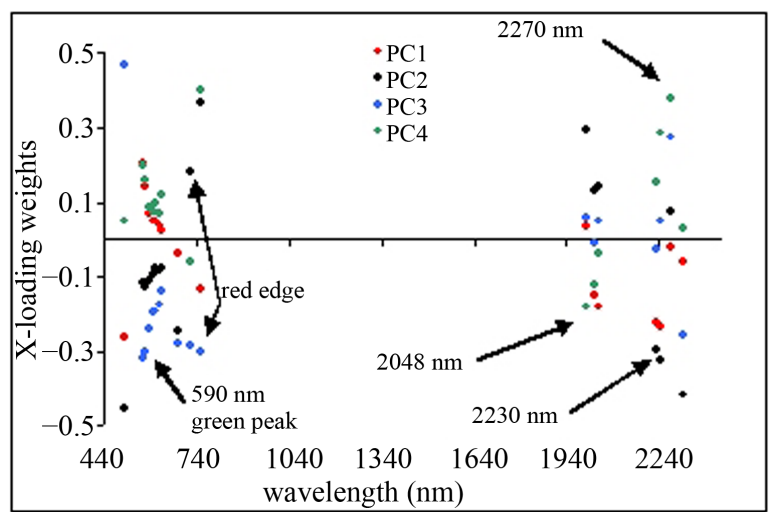

(c)

Figure 6. PLSR X-loading weights for important wavelengths associated with PLSR models with the highest CVs for digestibility for (a) original field spectra (ASD-2002-BNA-sig) and field spectra binned to (b) HyMap (LOG1R-D-sig) and (c) Hyperion (CR-D-sig) band pass functions.

Table 4. PLSR statistics for data subsets illustrated in Figure 7 (HyMap spectra) and Figure 8 (Hyperion spectra). Includes number of samples (n), slope (of regression line), offset, correlation coefficient R, root mean square error of prediction (RMSEP from full cross validation :leave-one-out:), standard error of prediction (SEP), bias, number of principal components (PCs).

\begin{tabular}{ccccccccc}
\hline Data subsetname & n & slope & offset & Correlation Coefficient R & RMSEP & SEP & bias & PCs \\
\hline CP-HyM-NONE-R-D-sig & 56 & 0.78 & 2.39 & 0.87 & 1.44 & 1.46 & 0.01 & 5 \\
Dig-HyM-2000-MNF-R & 56 & 0.84 & 9.52 & 0.91 & 2.42 & 2.44 & 0.07 & 9 \\
Lig-HyM-2000-HYCORR-EFF-BNA-D-sig & 56 & 0.74 & 1.29 & 0.86 & 0.95 & 0.96 & 0.00 & 3 \\
Cell-HyM-2000-NONE-CR-D-sig & 56 & 0.66 & 9.68 & 0.76 & 1.17 & 1.18 & 0.02 & 5 \\
CP-Hyp-MNF-EFF-CR-D-sig & 46 & 0.69 & 2.70 & 0.80 & 1.31 & 1.33 & 0.00 & 4 \\
Dig-Hyp-MNF-R-D-sig & 46 & 0.78 & 13.35 & 0.86 & 2.28 & 2.30 & 0.02 & 4 \\
Lig-Hyp-NONE-BNA-sig & 46 & 0.30 & 5.07 & 0.47 & 2.94 & 2.97 & -0.03 & 5 \\
Cell-Hyp-NONE-R-D-sig & 46 & 0.62 & 9.76 & 0.75 & 3.11 & 3.14 & 0.00 & 3 \\
\hline
\end{tabular}

predicted values for lignin have a different shape than the linear

\subsection{Comparison of the Different Spectrometer Results}

The qualitative threshold for predictive capacity of models of CV $>4.1$ was achieved for digestibility with ASD field and HyMap spectra, for crude protein and lignin only with the full set of HyMap spectra, and for cellulose with Hyperion-convolved field spectra (Table 3). Since R values $>0.8$ convert to coefficients of determination of 0.64 , predictive equations with this level of fit could have qualitative utility, but would be of limited value for 


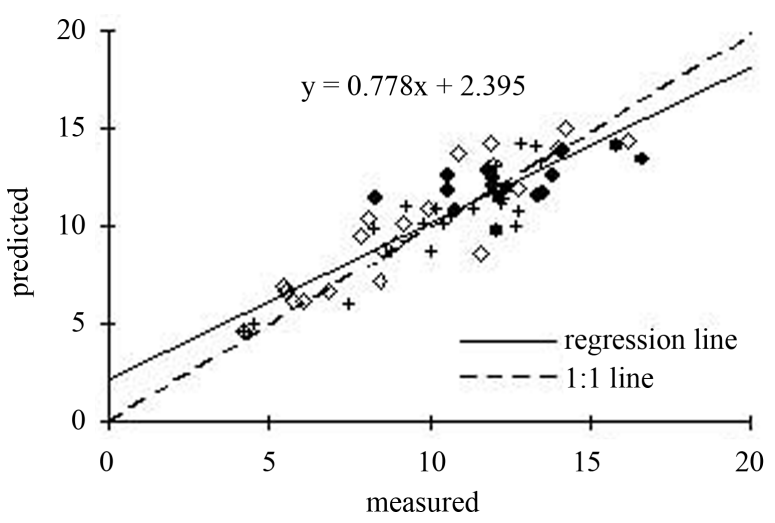

(a)

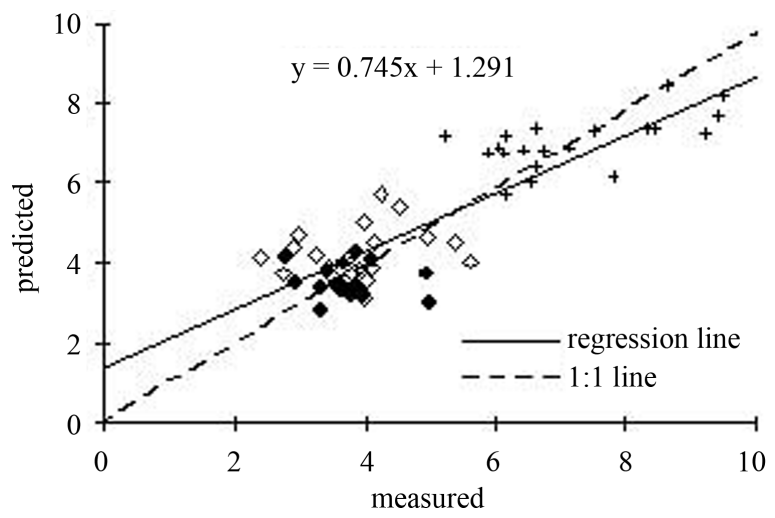

(c)

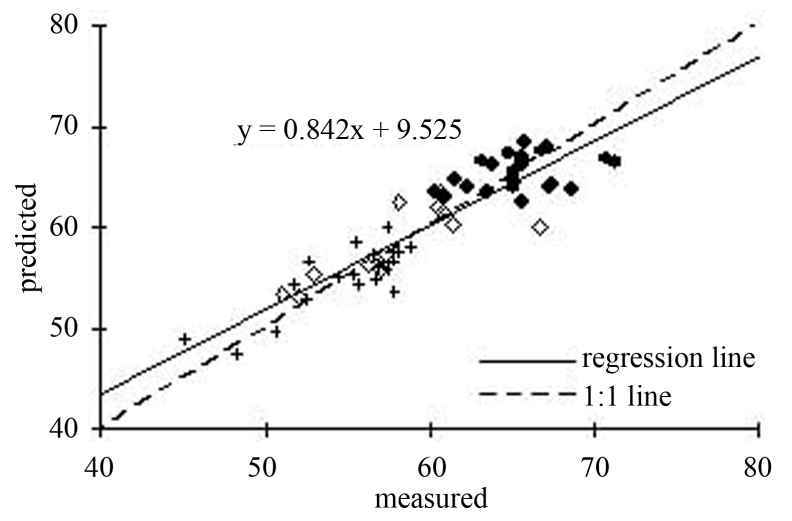

(b)

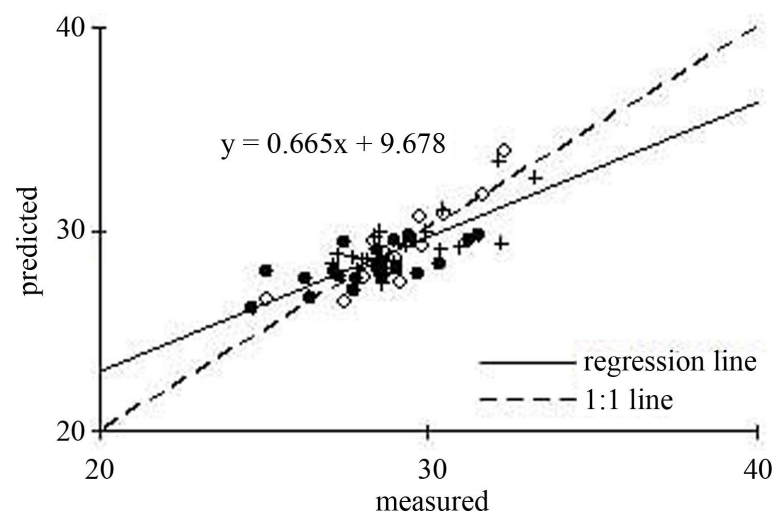

(d)

Figure 7. Plots of PLSR prediction results for the HyMap spectra for the December 2000 pasture quality attributes. (a) Crude protein (NONE and R-D-sig); (b) Digestibility (MNF and R); (c) Lignin (HYCORR-EFFORT and BNA-D-sig); (d) Cellulose (NONE and CR-D-sig). The diamonds denote data from PVI, the filled diamonds data from Ellinbank and crosses data from Vasey.

quantitative prediction. For prediction model errors need to be put in context both from a confidence perspective and in relation to measured and predicted ranges. Confidence intervals for prediction are as a rule of thumb given by $\pm 1.96 *$ RMSEP ([55] Martens and Martens, 2001), i.e. an approximate 95\% confidence interval for a predicted value. The models with the highest CVs for digestibility would produce $95 \%$ confidence interval of $\pm 7.7 \%$ for ASD field spectra, $\pm 5.3 \%$ for all HyMap spectra, and $\pm 4.8 \%$ from HyMap spectra from 2000 . These confidence intervals represent between 30 and $40 \%$ of the observed field data range from this study (Table 2). The confidence intervals for the models with the highest CVs for crude protein and cellulose represent about $40 \%-42 \%$ of the observed field data range depending on data subset. The corresponding confidence intervals for the models with the highest CVs for the other two attributes are: lignin, $\pm 1.1 \%$ and $48 \%$ of observed range for HyMap-all; cellulose, $\pm 3.9 \%$ and $41 \%$ of observed range for ASD field spectra binned to Hyperion; and crude protein, $\pm 2.8 \%$ equating to $41 \%$ of observed range for the HyMap-all data.

The PLSR X-loadings identify the most sensitive wavelengths for the models with the highest CVs for HyMap and Hyperion (Figure 9). In general, whilst the same broad regions were important for both HyMap and Hyperion, the wavelengths were often different. These regions were the green peak, chlorophyll well and red edge; the 1600 - $1800 \mathrm{~nm}$ region; and the 2000 - $2300 \mathrm{~nm}$ region. Similar wavelengths were often selected among crude protein, cellulose and digestibility; e.g., 2240, 2270 and 2230 with HyMap (Figures 9(a) (c) and (e); crude protein, digestibility and cellulose), and 2168 with Hyperion (Figures 9(b) and (d); for crude protein and digestibility).

\section{Discussion and Conclusions}

This study has shown that with the advent of next-generation hyperspectral airborne and satellite systems, 


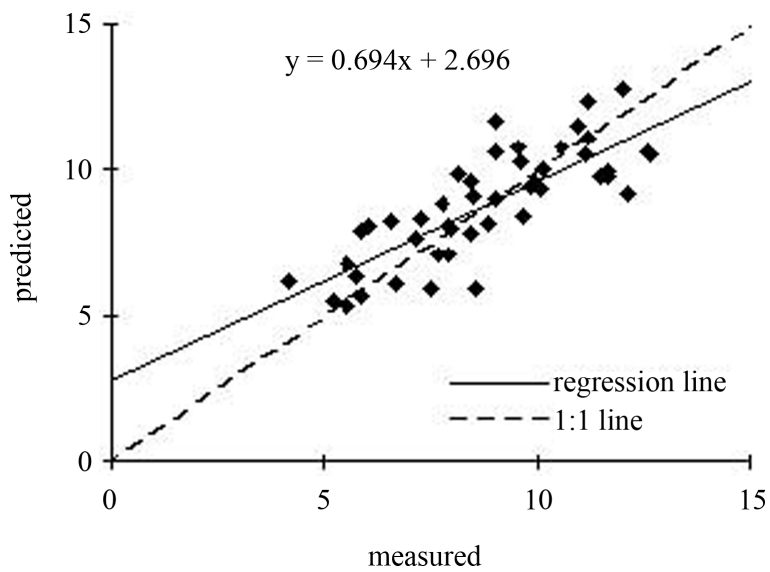

(a)

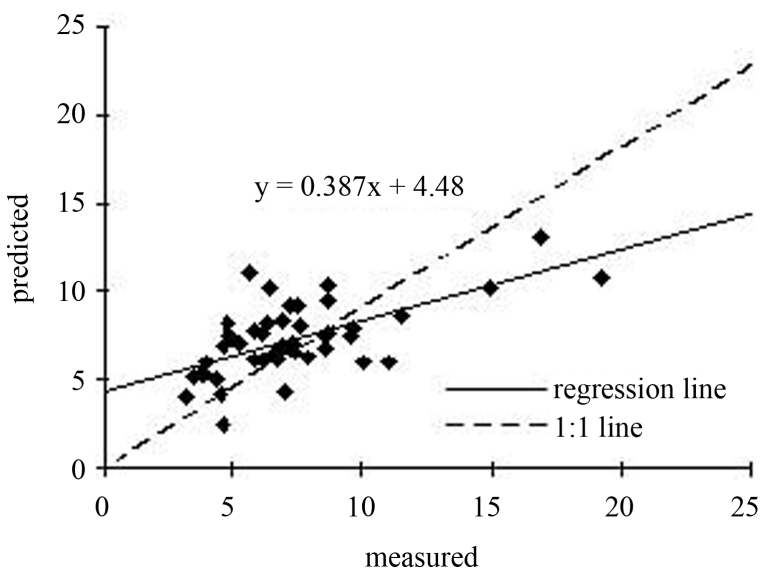

(c)

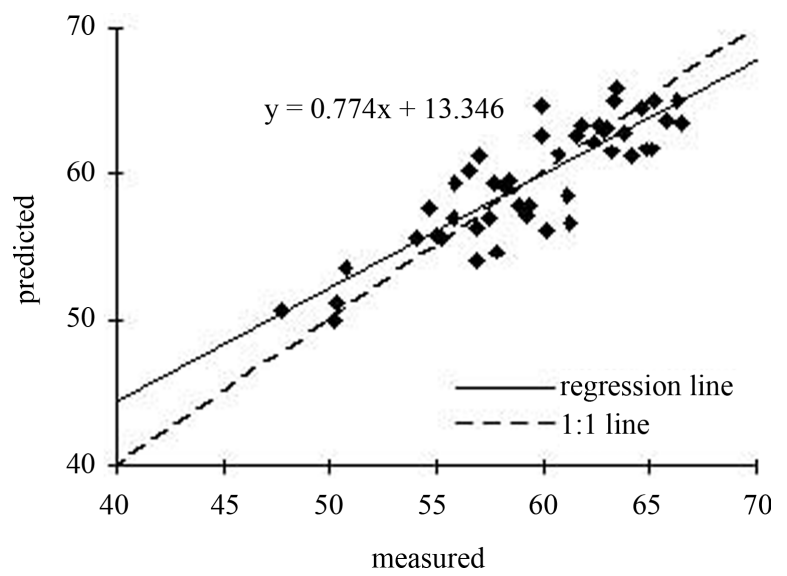

(b)

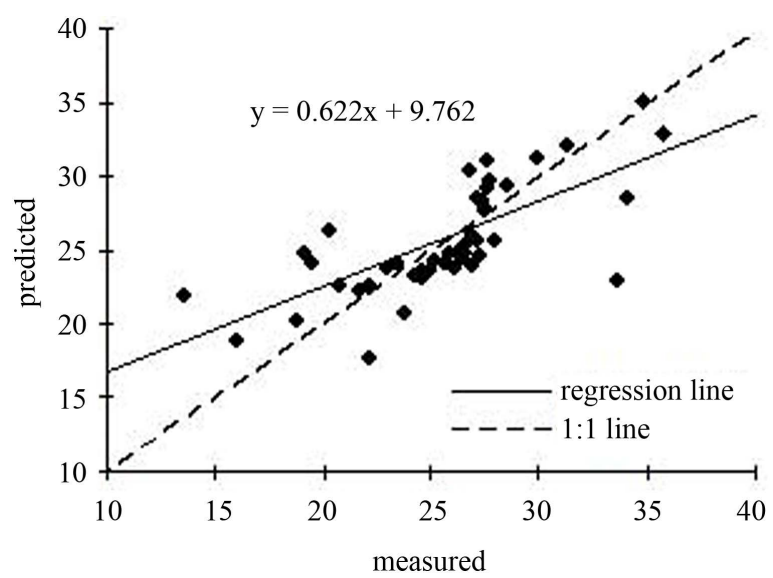

(d)

Figure 8. Plots of PLSR prediction results for the Hyperion 2002 models (post-atmospheric treatment and spectral transform): (a) Crude protein (MNF-EFF and CR-D-sig); (b) Digestibility (MNF and R-D-sig); (c) Lignin (NONE and BNA-sig); and (d) Cellulose (NONE and R-D-sig). The diamonds denote data from PVI, the filled diamonds data from Ellinbank and crosses data from Vasey.

combined with predictive models of crude protein content, cellulose concentration and digestibility better characterization of pasture quality and it's spatial variability can be derived for temperate pastures. The prediction statistics obtained here, were quite similar to those obtained by [1] for crude protein and ADF with field spectra, but not as good as those obtained by [34] [35], although that latter worked with leaf level analysis. However, the results demonstrate strong potential for development of specific models for crude protein, lignin, cellulose and digestibility from field, airborne and spaceborne spectrometers in temperate pastures.

The main wavelengths selected in the best predictive models for the image spectra were located in the chlorophyll pigment and red edge regions, in the 1600 - $1800 \mathrm{~nm}$ region, and in the 2000 - $2300 \mathrm{~nm}$ ligno-cellulose-protein region of the spectrum. The three major absorption features at approximately 480, 670 and $1200 \mathrm{~nm}$ are sensitive to chlorophyll a and b electron transitions, chlorophyll absorption and water [19]. The fourth main absorption feature of vegetation is located between $1652-1770 \mathrm{~nm}$ as the first overtones of $\mathrm{CH}$ bonds for nitrogen, protein, lignin and cellulose occur in this region [13] [59]. The fifth feature, in the region between 2006 2196, is related to protein, cellulose and lignin chemical overtones. Nitrogen, protein, lignin and cellulose all contribute to the sixth feature. In addition, the spectral region between 2260 - $2280 \mathrm{~nm}$ appears consistently in calibration equations for digestibility [60]. This is also the region where differences in spectral response make discrimination between senescent vegetation/litter and soil possible [61]. The wavelengths selected varied between the sensor/spectra types. This could be partly explained by the different band passes of the sensors and may stem from differences in band pass function attributes such as the Full Width Half Maximum-FWHM, Central Wave 


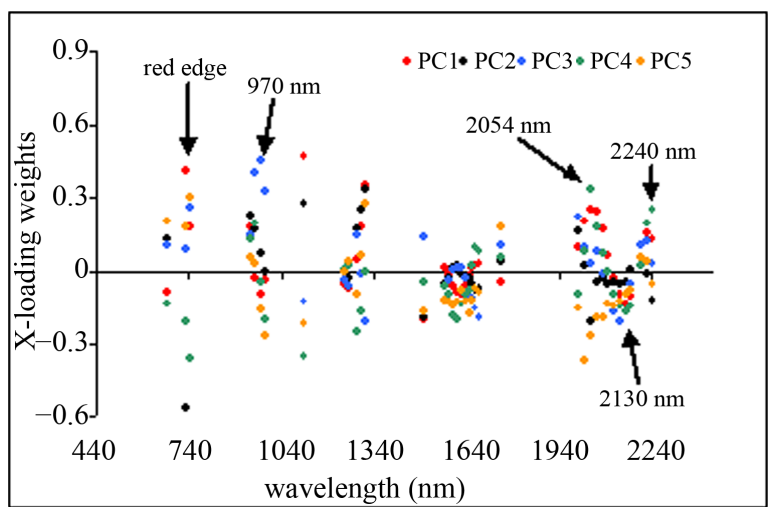

(a)

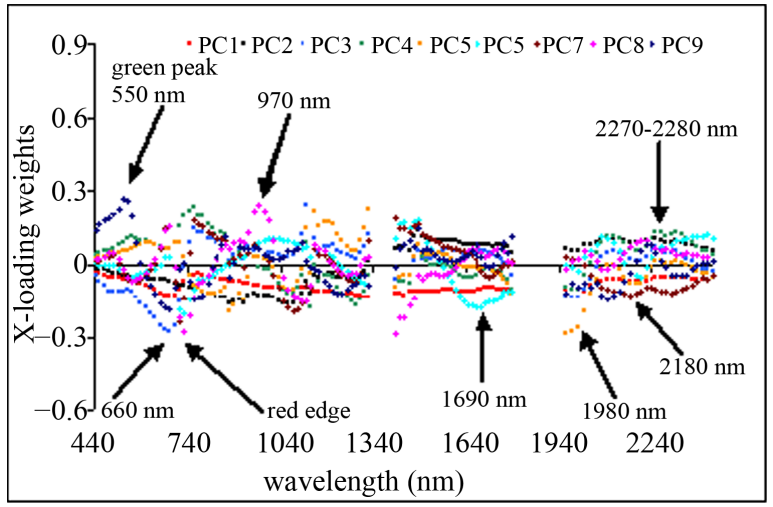

(c)

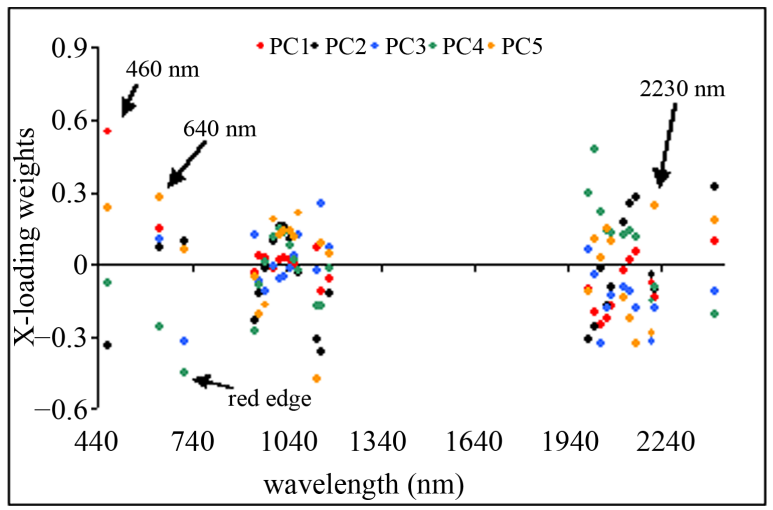

(e)

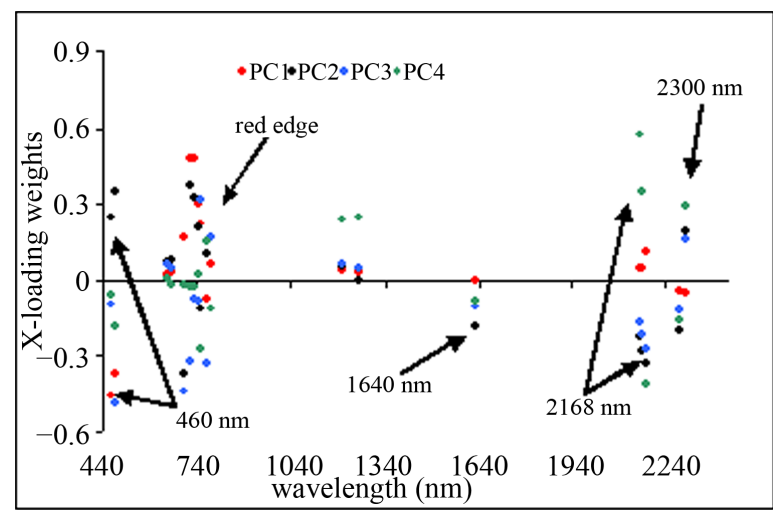

(b)

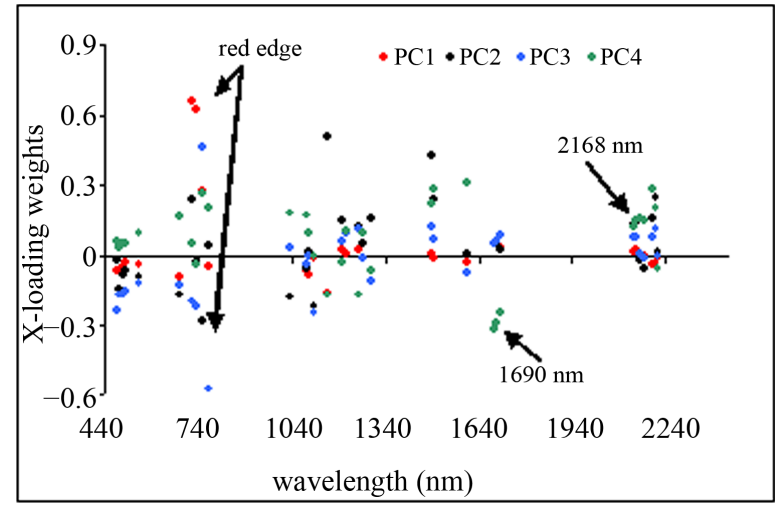

(d)

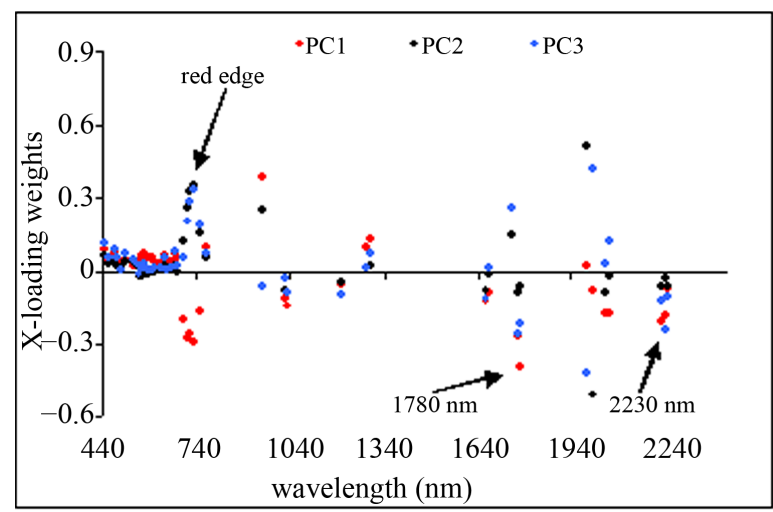

(f)

Figure 9. X-loadings for the models from PLSR between image spectra and pasture quality attributes. (a) HyMap-2000 (NONE and R-D-sig), crude protein; (b) Hyperion 2002 (MNF-EFF and R-D-sig), crude protein; (c) HyMap 2000 (MNF and R), digestibility; (d) Hyperion 2002 (MNF and R-D-sig), digestibility; (e) HyMap 2000 (NONE and CR-D-sig), cellulose; and (f) Hyperion 2002 (NONE and R-D-sig), cellulose.

Length - CWL. It could also be a function of radiometric resolution differences between the sensors, transformations but also because of varying sample and spectra composition.

These results confirm the premise that quality attributes related to fibre and digestibility are best predicted by a combination of indirect correlated pigment changes and direct absorption features. The study showed that digestibility can be predicted at a reasonable confidence interval using both airborne HyMap and spaceborne Hyperion image data. The lower predictive capacity of the model with the highest CV for lignin, tends to confirm the findings of [29] and [30] who suggest that leaf level absorptions for lignin are poorly propagated to the canopy level in heterogeneous canopies and particularly those with mixed live and senescent material. Many grazed 
pastures have vertically heterogeneous canopies made up of a mixture of green leaves, dead leaves, dead stems and mixed plant types. Both cellulose and lignin may be better predicted in very uniform, single species forage canopies.

The difference in IFOV and signal to noise ratio (SNR) between field, airborne and spaceborne spectrometers may introduce some biases and scaling effects into the predictive models that add to uncertainty. Hence, it would be expected that models from the ASD field spectra, with much higher SNR and lack of disturbing atmosphere would show lower errors, higher correlation and higher CVs than HyMap spectra.

Walking averages over established areas which, at minimum, cover a $3 \times 3$ pixel window would be ideal for comparison with HyMap data. However, in this study, with both high resolution (2.6 - $2.9 \mathrm{~m}$ ) and medium resolution (30 m) pixel acquisitions, and some uncertainty, a mix of field spectra acquisition methods was essential to ensure a suitable collection of spectra was acquired. Some other factors that can contribute to model uncertainty include spatial position of sampling, limited number of samples and attribute ranges, as well as the different ranges for field spectra compared to image spectra.

Ideally models should be based on wide ranges encompassing values likely to be encountered in future predictions to provide stability. However, if the wide attribute range as in the case of HyMap-all data subset produces low RMSEP values and high correlations, a visual inspection of the prediction model results (e.g. score plots) needs to be performed to ascertain that the relationship is not based on quite separate sample populations.

The assessment of the usefulness of predictive relationships between spectral information and pasture quality attributes should not be limited to statistical measures. The potential application must be taken into account. In particular, the predictive relationships with moderate confidence intervals may still be useful for categorizing pasture quality into range classes rather than continuous values, and for establishing whether the pasture was above or below a threshold value to some productivity benchmark. Some of the models derived for digestibility produced CVs high enough to indicate usefulness in a qualitative sense (CV > 4.1). The results obtained here for crude protein, cellulose and digestibility were similar to those of [1] crude protein and ADF. Models with a confidence interval for digestibility of about 5\% for predictions from both HyMap and Hyperion imagery would provide an excellent complement to biomass and growth rate information currently retrievable.

If the $\pm 5 \%$ confidence interval of prediction is applied to known ranges of digestibility corresponding to different pasture types and general seasonal phenological stages (Table 5), it can be seen that the models with the highest CVs HyMap and Hyperion could predict the major differences at intervals of $\sim 10$ digestibility units. The seasonal timing is general and can also occur at other times of year, for example in regrowth after early harvests. Examples of the types of maps that could be produced for inclusion in, for example precision farming systems, are shown in Figure 10. Using the PLSR models for the HyMap-all datasets with the highest CVs, predicted values were obtained for HyMap images of a paddock adjacent to the PVI farm, the results here shown in 9 classes ranging from low (red) to high (purple) for a) digestibility and b) crude protein.

Based on the range of values used to indicate low, moderate and high quality from FEEDTEST®, a spatial distribution of temperate pasture digestibility in three classes, $>72 \%, \sim 60 \%-72 \%,<60 \%$ and crude protein values in two classes $>10 \%$ and under $10 \%$, could potentially be provided by the best models. Such a product would be useful if it was able to be supplied on a timely and regular basis. At present there are no current or planned space borne hyperspectral sensors that could deliver such data, except perhaps for small areas under dedicated tasking.

In temperate pastures, the seasonal pattern of feed quality can often be predicted on the basis of rainfall, growing conditions and management. Feed testing can be routinely carried out on dried, ground samples using Near Infrared Reflectance Spectroscopy [62]. However, grazing enterprises would greatly benefit from hyperspectral imagery products that map the spatial pattern of pasture quality. Hence there is a clear role for a new generation of imaging spectrometers that can be applied to agricultural monitoring.

\section{Acknowledgements}

This research was supported by the Co-operative Research Center for Greenhouse Accounting. The authors wish to thank Mr Geoff Saul and the staff of the Pastoral and Veterinary Research Laboratory, Hamilton, Victoria, Dr Richard Eckard and staff, Ellinbank Research Station, Victoria, and Paul Daniel and Dr Catherine Ticehurst and other members of the Remote Sensing of Land and Water group, CSIRO, Canberra, for their support and assistance with this project. The authors also thank Peter Flinn and staff at FEEDTEST for help and useful discussions. 
Table 5. Pasture species and plant component digestibility in relation to confidence intervals from the models with highest CV's for digestibility — different shading indicates digestibility class separated at confidence interval. (Sources: [63]-[65])

\begin{tabular}{|c|c|c|c|}
\hline $\begin{array}{c}\text { Digestibility Class } \\
\text { and Range }(\%)\end{array}$ & $\begin{array}{c}\text { Confidence Interval } \\
\text { Digestibility 5\% (DM) }\end{array}$ & Pasture Species & Plant Components/Seasonal Timing ${ }^{2,3}$ \\
\hline $\begin{array}{l}\text { Very high } \\
75-85\end{array}$ & & $\begin{array}{l}\text { white clover, Persian clover, tetraploid } \\
\text { and hybrid biennial ryegrass }{ }^{1}\end{array}$ & April-July: young leaves \\
\hline $\begin{array}{l}\text { High } \\
70-80\end{array}$ & & $\begin{array}{l}\text { perennial ryegrass, phalaris, } \\
\text { tall fescue, alfalfa, subterranean } \\
\text { clover, Balansa clover, Cape weed }\end{array}$ & April-July: young leaves \\
\hline $\begin{array}{l}\text { Moderate } \\
65-75\end{array}$ & & $\begin{array}{l}\text { orchard grass, annual Bromus spp., barley } \\
\text { grass }\end{array}$ & \\
\hline $60-70$ & & wallaby grass, fog grass, weeping grass ${ }^{2}$ & August: old leaf/young stems \\
\hline $\begin{array}{l}\text { Low } \\
55-65\end{array}$ & & $\begin{array}{l}\text { onion grass, sweet vernal, fox/rats tail } \\
\text { fescue, spear grass, weeping grass }{ }^{1} \text {, } \\
\text { kangaroo grass, silver grass. }\end{array}$ & \\
\hline $40-55$ & & $\begin{array}{l}\text { Senescent annual grasses and forbs of } \\
\text { all types }\end{array}$ & \\
\hline $30-40$ & & $\begin{array}{l}\text { All material in absence of summer rain to } \\
\text { support perennial species }\end{array}$ & \\
\hline
\end{tabular}
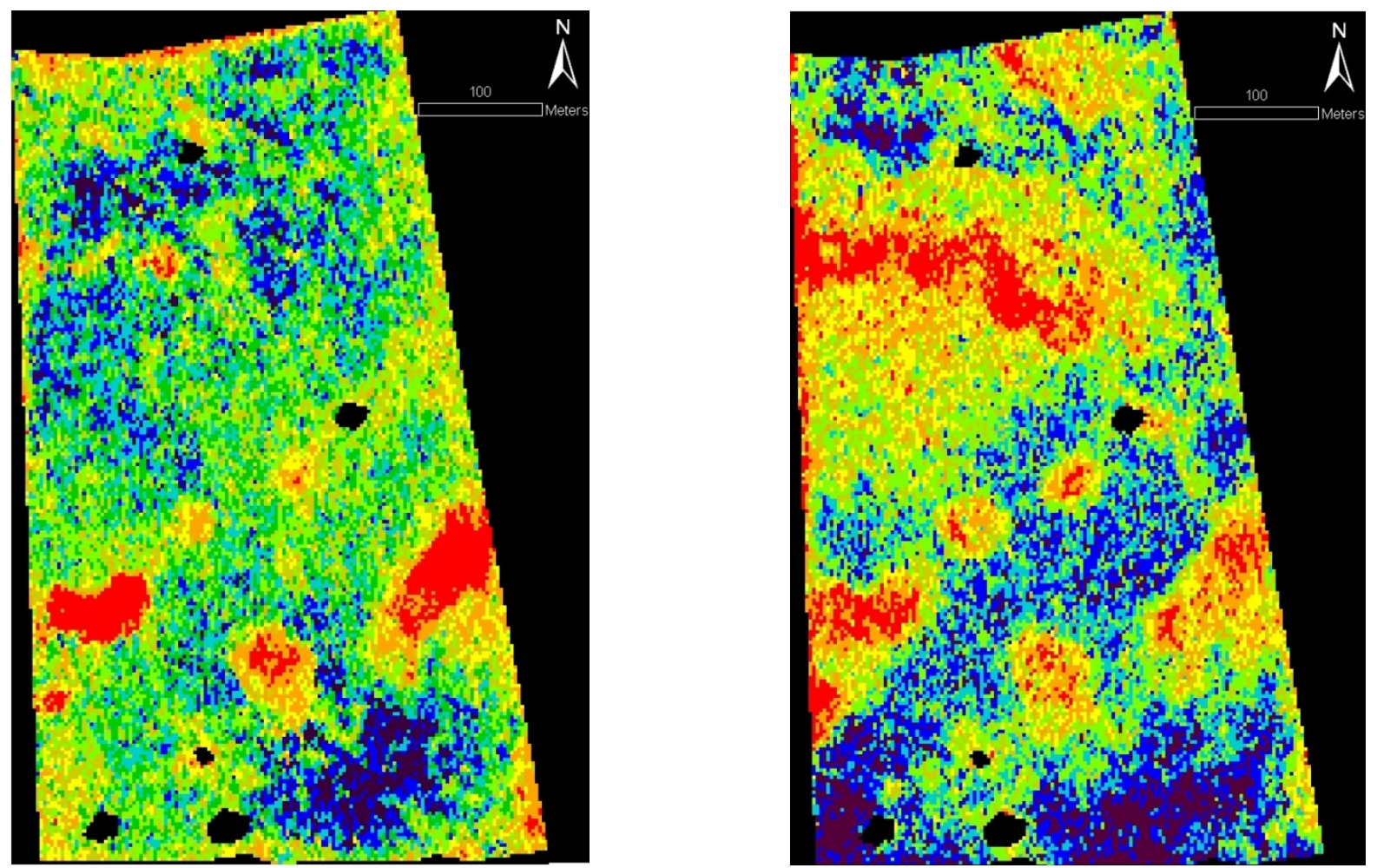

Figure 10. Maps of a paddock showing spatial distribution of value classes predicted using PLSR developed models for (a) digestibility (HyMap-all, data range 43\% - 82\%). (b) Crude protein (HyMap-all data range 3\% - 18\%), 9 class colour scale ranging from low to high (red-yellow-green-blue-purple). 


\section{References}

[1] Kawamura, K., Watanabe, N., Sakanoue, S. and Inoue, Y. (2008) Estimating Forage Biomass and Quality in a Mixed Sown Pasture Based on Partial Least Squares Regression with Waveband Selection. Grassland Science, 54, 131-145. http://dx.doi.org/10.1111/j.1744-697X.2008.00116.x

[2] Numata, I., Roberts, D.A., Chadwick, O.A., Schimel, J.P., Galvao, L.S. and Soares, J.V. (2008) Evaluation of Hyperspectral Data for Pasture Estimate in the Brazilian Amazon Using Field and Imaging Spectrometers. Remote Sensing of Environment, 112, 1569-1583. http://dx.doi.org/10.1016/j.rse.2007.08.014

[3] Pearson, R.L., Tucker, C.J. and Miller, L.D. (1976) Spectral Mapping of Shortgrass Prairie Biomass. Photogrammetric Engineering and Remote Sensing, 42, 317-323.

[4] Richardson, A.J., Everitt, J.H. and Gausman, H.W. (1983) Radiometric Estimation of Biomass and Nitrogen Content of Alicia Grass. Remote Sensing of Environment, 13, 179-184. http://dx.doi.org/10.1016/0034-4257(83)90021-4

[5] Wylie, B.K., Harrington, J.A., Prince, S.D. and Denda, I. (1991) Satellite and Ground-Based Pasture Production Assessment in Niger: 1986-1988. International Journal of Remote Sensing, 12, 1281-1300. http://dx.doi.org/10.1080/01431169108929726

[6] Todd, S.W., Hoffer, R.M. and Milchunas, D.G. (1998) Biomass Estimation on Grazed and Ungrazed Rangelands Using Spectral Indices. International Journal of Remote Sensing, 19, 427-438. http://dx.doi.org/10.1080/014311698216071

[7] Davidson, A. and Csillag, F. (2001) The Influence of Vegetation Index and Spatial Resolution on a Two-Date Remote Sensing-Derived Relation to C4 Species Coverage. Remote Sensing of Environment, 75, 138-151. http://dx.doi.org/10.1016/S0034-4257(00)00162-0

[8] Hill, M.J., Donald, G.E., Hyder, M.W. and Smith, R.C.G. (2004) Estimation of Pasture Growth Rates in South Western Australia from AVHRR NDVI and Climate Data. Remote Sensing of Environment, 93, 528-545. http://dx.doi.org/10.1016/j.rse.2004.08.006

[9] Edirisinghe, A., Hill, M.J., Donald, G.E., Henry, D. and Hyder, M. (2011) Quantitative Mapping of Pasture Biomass Using Satellite Imagery. International Journal of Remote Sensing, 32, 2699-2724. http://dx.doi.org/10.1080/01431161003743181

[10] Norris, K.H., Barnes, R.F., Moore, J.E. and Shenk, J.S. (1976) Predicting Forage Quality by Infrared Reflectance Spectroscopy. Journal of Animal Science, 43, 889-897.

[11] Murray, I. (1989) Application of NIRS in Agriculture. Proceedings of the 2nd International Near Infrared Spectroscopy Conference, Tsukuba, 29 May-2 June 1989, 11-20.

[12] Danieli, P.P., Carlini, P., Benabucci, U. and Ronchi, B. (2004) Quality Evaluation of Regional Forage Resources by Means of Near Infrared Reflectance Spectroscopy. Italian Journal of Animal Science, 3, 363-376.

[13] Asner, G.P. (2004) Chapter 2: Biophysical Remote Sensing of Signatures of Arid and Semiarid Ecosystems. In: Ustin, S.L., Ed., Remote Sensing for Natural Resources Management and Environmental Monitoring: Manual of Remote Sensing, John Wiley \& Sons, Inc., Hoboken, 53-109.

[14] Asner, G.P. and Martin, R.E. (2008) Airborne Spectranomics: Mapping Canopy and Taxonomic Diversity in Tropical Forests. Frontiers in Ecology and the Environment, 7, 269-276.

[15] Ball, D.M., Collins, M., Lacefield, G.D., Martin, N.P., Mertens, D.A., Olson, K.E., Putnam, D.H., Undersander, D.J. and Wolf, M.W. (2001) Understanding Forage Quality. American Farm Bureau Federation Publication 1-01, American Farm Bureau Federation, Park Ridge.

[16] Schroeder, J.W. (1994) Interpreting Forage Analysis. North Dakota State University. http://www.ext.nodak.edu/extpubs/plantsci/hay/r10802.htm

[17] Sullivan, J.T. (1973) Drying and Storing Herbage as Hay. In: Butler, G.W. and Bailey, R.W., Eds., Chemistry and Biochemistry of Herbage, Vol. 3, Academic Press, London and New York, 1-28.

[18] Van Soest, P.J. (1985) Composition, Fiber Quality and Nutritive Value of Forages. Chapter 44. In: Heath, M.E., Barnes, E.M. and Metcalfe, D.S., Eds., Forages-The Science of Grassland Agriculture, Iowa State University Press, Ames, 412-444.

[19] Curran, P.J., Dungan, J.L. and Peterson, D.L. (2001) Estimating the Foliar Biochemical Concentration of Leaves with Reflectance Spectrometry: Testing the Kokaly and Clark Methodologies. Remote Sensing of Environment, 76, 349-359. http://dx.doi.org/10.1016/S0034-4257(01)00182-1

[20] Kokaly, R.F. and Clark, R.N. (1999) Spectroscopic Determination of Leaf Biochemistry Using Band-Depth Analysis of Absorption Features and Stepwise Multiple Linear Regression. Remote Sensing of Environment, 67, 267-287. http://dx.doi.org/10.1016/S0034-4257(98)00084-4

[21] Filella, I. and Peñuelas, J. (1994) The Red Edge Position and Shape as Indicators of Plant Chlorophyll Content, Bio- 
mass and Hydric Status. International Journal of Remote Sensing, 15, 1459-1470. http://dx.doi.org/10.1080/01431169408954177

[22] Jago, R.A., Cutler, M.E. and Curran, P.J. (1999) Estimation of Canopy Chlorophyll Concentration from Field and Airborne Spectra. Remote Sensing of Environment, 68, 217-224. http://dx.doi.org/10.1016/S0034-4257(98)00113-8

[23] Garcia-Ciudad, A., Ruano, A., Becerro, F., Zabalgogeazcoa, I., Vazquez de Aldana, B.R. and Garcia-Criado, B. (1999) Assessment of the Potential of NIR Spectroscopy for the Estimation of Nitrogen Content in Grasses from Semiarid Grasslands. Animal Feed Science and Technology, 77, 91-98. http://dx.doi.org/10.1016/S0377-8401(98)00237-5

[24] Lamb, D.W., Steyn-Ross, M., Schaares, P., Hanna, M.M., Silvester, W. and Steyn-Ross, A. (2002) Estimating Leaf Nitrogen Concentration in Ryegrass (Lolium spp.) Pasture Using the Chlorophyll Red-Edge: Theoretical Modelling and Experimental Observations. International Journal of Remote Sensing, 23, 3619-3648. http://dx.doi.org/10.1080/01431160110114529

[25] Dash, J. and Curran, P.J. (2004) The MERIS Terrestrial Chlorophyll Index. International Journal of Remote Sensing, 25, 5403-5413. http://dx.doi.org/10.1080/0143116042000274015

[26] Dash, J. and Curran, P.J. (2007) Evaluation of the MERIS Terrestrial Chlorophyll Index (MTCI). Advances in Space Research, 39, 100-104. http://dx.doi.org/10.1016/j.asr.2006.02.034

[27] Pinzon, J.E., Ustin, S.L., Castaneda, C.M. and Smith, M.O. (1998) Investigation of Leaf Biochemistry by Hierarchical Foreground/Background Analysis. IEEE Transactions on Geoscience and Remote Sensing, 36, 1913-1927. http://dx.doi.org/10.1109/36.729363

[28] Soukupova, J., Rock, B.N. and Albrechtova, J. (2002) Spectral Characteristics of Lignin and Soluble Phenolics in the Near Infrared-A Comparative Study. International Journal of Remote Sensing, 23, 3039-3055. http://dx.doi.org/10.1080/01431160110104683

[29] Serrano, L., Peñuelas, J. and Ustin, S.L. (2002) Remote Sensing of Nitrogen and Lignin in Mediterranean Vegetation from AVIRIS Data: Decomposing Biochemical from Structural Signals. Remote Sensing of Environment, 81, 355-364. http://dx.doi.org/10.1016/S0034-4257(02)00011-1

[30] Asner, G.P., Wessman, C.A., Bateson, C.A. and Privette, J.L. (2000) Impact of Tissue, Canopy and Landscape Factors on the Hyperspectral Reflectance Variability of Arid Ecosystems. Remote Sensing of Environment, 74, 69-84. http://dx.doi.org/10.1016/S0034-4257(00)00124-3

[31] Lewis, M., Jooste, V. and de Gasparis, A.A. (2001) Discrimination of Arid Vegetation with Airborne Multispectral Scanner Hyperspectral Imagery. IEEE Transactions on Geoscience and Remote Sensing, 39, 1471-1479. http://dx.doi.org/10.1109/36.934078

[32] Ben-Dor, E., Chabrillat, S., Demattê, J.A.M., Taylor, G.R., Hill, J., Whiting, M.L. and Sommer, S. (2009) Using Imaging Spectroscopy to Study Soil Properties. Remote Sensing of Environment, 113, S38-S55. http://dx.doi.org/10.1016/j.rse.2008.09.019

[33] Asner, G.P. and Lobell, D.B. (2000) A Biogeophysical Approach for Automated SWIR Unmixing of Soils and Vegetation. Remote Sensing of Environment, 74, 99-112. http://dx.doi.org/10.1016/S0034-4257(00)00126-7

[34] Schut, A.G.T., Lokhorst, C., Hendriks, M.M.W.B., Kornet, J.G. and Kasper, G. (2005) Potential of Imaging Spectroscopy as Tool for Pasture Management. Grass and Forage Science, 60, 34-45. http://dx.doi.org/10.1111/j.1365-2494.2005.00449.x

[35] Schut, A.G.T., Thompson, A.N., Gherardi, S. and Metternicht, G. (2006) Seasonal Changes in Pasture Quality in Mediterrenean Regions in Australia. 13th Australian Agronomy Conference, Perth, 10-14 September 2006. http://www.regional.org.au/au/asa/2006/poster/technology/4665 schutagt.htm

[36] Thulin, S.M., Hill, M.J., Held, A.H., Jones, S. and Woodgate, P. (2012) Hyperspectral Determination of Feed Quality Constituents in Temperate Pastures: Effect of Processing Methods on Predictive Relationships from Partial Least Squares Regression. International Journal of Applied Earth Observation and Geoinformation, 19, 322-334. http://dx.doi.org/10.1016/j.jag.2012.06.006

[37] Mutanga, O. and Skidmore, A.K. (2004) Hyperspectral Band Depth Analysis for a Better Estimation of Grass Biomass (Cenchrus ciliaris) Measured under Controlled Laboratory Conditions. International Journal of Applied Earth Observation and Geoinformation, 5, 87-96. http://dx.doi.org/10.1016/j.jag.2004.01.001

[38] Mutanga, O., Skidmore, A.K., Kumar, L. and Ferwerda, J. (2005) Estimating Tropical Pasture Quality at Canopy Level Using Band Depth Analysis with Continuum Removal in the Visible Domain. International Journal of Remote Sensing, 26, 1093-1108. http://dx.doi.org/10.1080/01431160512331326738

[39] Cocks, T.D., Jenssen, R., Steward, A., Wilson, I. and Shields, T. (1998) The HyMap ${ }^{\mathrm{TM}}$ Airborne Hyperspectral Sensor: The System, Calibration and Performance. In The 1st EARSeL Workshop on Imaging Spectroscopy, University of Zurich, Zurich.

[40] Pearlman, J.S., Barry, P.S., Segal, C.S., Shepanski, J., Beiso, D. and Carman, S.L. (2003) Hyperion, a Space-Based 
Imaging Spectrometer. IEEE Transactions on Geoscience and Remote Sensing, 41, 1160-1173. http://dx.doi.org/10.1109/TGRS.2003.815018

[41] Barry, P. (2001) EO-1/Hyperion Science Data User's Guide. TRW Space, Defense \& Information Systems, Redondo Beach, CA.

[42] Apan, A. and Held, A. (2002) In-House Workshop on Hyperion Data Processing: Echoing the Sugarcane Project Experience. CSIRO Land and Water, Black Mountain Laboratories, Canberra.

[43] Datt, B. and Jupp, D.L.B. (2004) Hyperion Data Processing Workshop: Hands-On Processing Instructions. CSIRO Office of Space Science \& Applications Earth Observation Centre, Canberra.

[44] Datt, B., McVicar, T.R., Van Niel, T.G., Jupp, D.L.B. and Pearlman, J.S. (2003) Preprocessing EO-1 Hyperion Hyperspectral Data to Support the Application of Agricultural Indexes. IEEE Transactions on Geoscience and Remote Sensing, 41, 1246-1259. http://dx.doi.org/10.1109/TGRS.2003.813206

[45] Green, A.A., Berman, M., Switzer, P. and Craig, M.D. (1988) A Transformation for Ordering Multispectral Data in terms of Image Quality with Implications for Noise Removal. IEEE Transactions on Geoscience and Remote Sensing, 26, 65-74.

[46] Jupp, D.L.B., Datt, B., Lovell, J., Campbell, S. and King, E.A. (2002) Discussions around Hyperion Data: Background Notes for the Hyperion Data Users Workshop. CSIRO EOC, Canberra.

[47] Research Systems Inc. (2003) ENVI Online Help. Retrieved Help Manual for ENVI, RSI, Boulder, CO.

[48] Center for the Study of Earth from Space (CSES) (1999) Atmosphere Removal Program (ATREM). Version 3.1, User's Guide. CIRES, University of Colorado, CSES Center for the Study of Earth from Space, Boulder.

[49] Mason, P. (2000) HYCORR User’s Manual. CSIRO, Sydney.

[50] Boardman, J.W. (1998) Post-ATREM Polishing of AVIRIS Apparent Reflectance Data Using EFFORT: A Lesson in Accuracy versus Precision. In: Summaries of the 7th JPL Airborne Earth Science Workshop, 12-16 January 1998, Pasadena, CA. JPL Publication 97-21. Pasadena, CA, 1, 1-53.

[51] Tsai, F. and Philpot, W. (1998) Derivative Analysis of Hyperspectral Data. Remote Sensing of Environment, 66, 41-51. http://dx.doi.org/10.1016/S0034-4257(98)00032-7

[52] Huang, Z., Turner, B.J., Dury, S.J., Wallis, I.R. and Foley, W.J. (2004) Estimating Foliage Nitrogen Concentration from HYMAP Data Using Continuum Removal Analysis. Remote Sensing of Environment, 93, 18-29. http://dx.doi.org/10.1016/j.rse.2004.06.008

[53] Jupp, D.L.B. (2001) Discussion around Hyperion Data. http://www.eoc.csiro.au/hswww/oz_pi/docs/Hyp_Notes.pdf

[54] Schlerf, M., Atzberger, C., Udelhoven, T., Jarmer, T., Mader, S., Werner, W. and Hill, J. (2003) Spectrometric Estimation of Leaf Pigments in Norway Spruce Needles Using Band-Depth Analysis, Partial Least-Squares Regression and Inversion of a Conifer Leaf Model. 3rd EARSeL Workshop on Imaging Spectroscopy, Herrsching, 13-16 May, 559568.

[55] Martens, H. and Martens, M. (2001) Multivariate Analysis of Quality: An Introduction. John Wiley \& Sons, Chichester.

[56] Naes, T., Isaksson, T., Fearn, T. and Davies, T. (2002) A User-Friendly Guide to Multivariate Calibration and Classification. 1st Edition, NIR Publications, Chichester.

[57] Ollinger, S.V., Smith, M.L., Martin, M.E., Hallett, R.A., Goodale, C.L. and Aber, J.D. (2002) Regional Variation in Foliar Chemistry and N Cycling among Forests of Diverse History and Composition. Ecology, 83, 339-355.

[58] Park, R.S., Agnew, R.E., Gordon, F.J. and Steen, R.W.J. (1998) The Use of Near Infrared Reflectance Spectroscopy (NIRS) on Undried Samples of Grass Silage to Predict Chemical Composition and Digestibility Parameters. Animal Feed Science and Technology, 72, 155-167. http://dx.doi.org/10.1016/S0377-8401(97)00175-2

[59] Curran, P.J. (1989) Remote Sensing of Foliar Chemistry. Remote Sensing of Environment, 30, 271-278. http://dx.doi.org/10.1016/0034-4257(89)90069-2

[60] Gordon, F.J., Cooper, K.M., Park, R.S. and Steen, R.W.J. (1998) The Prediction of Intake Potential and Organic Matter Digestibility of Grass Silages by Near Infrared Spectroscopy Analysis of Undried Samples. Animal Feed Science and Technology, 70, 339-351. http://dx.doi.org/10.1016/S0377-8401(97)00087-4

[61] Nagler, P.L., Daughtry, C.S.T. and Goward, S.N. (2000) Plant Litter and Soil Reflectance. Remote Sensing of Environment, 71, 207-215. http://dx.doi.org/10.1016/S0034-4257(99)00082-6

[62] Park, R.S., Agnew, R.E., Gordon, F.J. and Barnes, R.J. (1999) The Development and Transfer of Undried Grass Silage Calibrations between Near Infrared Reflectance Spectroscopy Instruments. Animal Feed Science and Technology, 78, 325-340. http://dx.doi.org/10.1016/S0377-8401(98)00261-2

[63] Hill, R. (1999) PROGRAZE ${ }^{\circledR}$ : Profitable, Sustainable Grazing. Department of Natural Resources and Environment, 
Ballarat.

[64] Saul, G.R. (2006) Chapter 9: Livestock Production from Pastures. In: Nie, Z. \& Saul, G.R., Eds., Greener Pastures for South West Victoria, 2nd Edition, Victorian Department of Primary Industries, Hamilton, 80-89.

[65] Horizon Agriculture Pty. Ltd. (2005) Linking Science to Productive Solutions-Mean DM Digestibility. http://www.hzn.com.au/pasture_digestibility_estimates.php 